A11100 993025

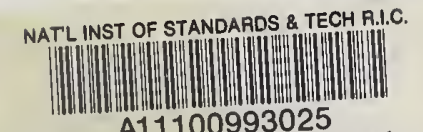

A11100993025

Leyendecker, Edgar V/Deslgn methods for

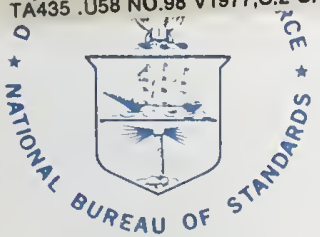

NBS BUILDING SCIENCE SERIES 98

U.S. DEPARTMENT OF COMMERCE / National Bureau of Standards

\title{
Design Methods for Reducing the Risk of Progressive
Collapse in Buildings Risk of Progressive
Collapse in Buildings
}

TA

435

U58

ivo, 98

1977

C.?

C., 2 


\section{The Building Science Series}

The Building Science Series disseminates technical information developed at the National Bureau of Standards on building materials, components, systems, and whole structures. The Scries presents research results. test methods, ant performance criteria related to the structural and environmental functions and the durability and safety characteristics of building elements and systems.

These publications, similar in style and content to the NBS Building Materials and Structures Reports (1938.59), are directed toward the manufacturing, design, construction, and research segments of the building industry, standards organizations, and officials responsible for building codes.

The material for this Series originates principally in the Center for Building Technology of the NBS Institute for Applied Technology. The publications are divided into three general groups: Buileling Systems and Processes; Health, Safety and Comfort; and Structures and Materials. For further information rcgarding these publications please contact the Program Planning and Liaison Unit, Center for Building Technology, Institute for Applied Technology, National Bureau of Standards, Washington, L.C. 20234. 
The research and studies forming the basis of this report were conducted under Inter-Agency Agreement No H-37-72, Task 408, sponsored by the Department of Housing and Urban Development (HUD). The statements and conclusions contained herein are those of the National Bureau of Standards and do not necessarily reflect the technical view or policies of HUD. 
SEP $\quad W$

rotace Design Methods for Reducing the Risk

TA $435^{\circ}$ of Progressive Collapse in Buildings

.058

no. 98

1977

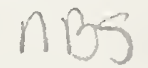

Buidre

suance

C.2 Edgar V. Leyendecker and

Bruce R. Ellingwood

Center for Building Technology

Institute for Applied Technology

National Bureau of Standards

Washington, D.C. 20234

Prepared for

Divison of Energy, Building Technology and Standards

Office of Policy Development and Research

Department of Housing and Urban Development

Washington, D.C. 20410

Supersedes NBSIR 76-1106

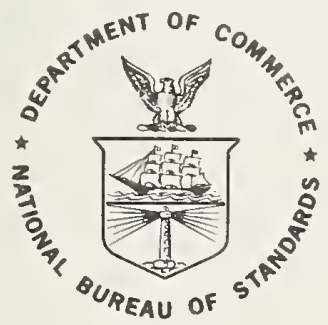

U.S. DEPARTMENT OF COMMERCE, Juanita M. Kreps, Secretary

Dr. Betsy Ancker-Johnson, Assistant Secretary for Science and Technology NATIONAL BUREAU OF STANDARDS. Ernest Ambler. Acting Director

Issued April 1977 


\section{Library of Congress Cataloging in Publication Data}

Leyendecker, E V

Design methods for reducing the risk of progressive collapse in buildings.

(NBS building science series ; 98)

"Supersedes NBSIR 76-1106."

Bibliography: p.

Supt. of Docs. no.: C13.29/2:98

1. Structural design. 2. Building failures. I. Ellingwood, Bruce, joint author. II. United States. Dept. of Housing and Urban Development. Division of Energy, Building Technology and Standards. III. Title. 1V. Series: United States. National Bureau of Standards. Building science series ; 98.

TA435.U58 no. 98 [TA658.2] 690'.012s [690] 77-608039

\section{National Bureau of Standards Building Science Series 98}

Nat. Bur. Stand. (U.S.), Bldg. Sci. Ser. 98, 68 pages (Apr. 1977)

CODEN: BSSNBV 


\section{NOTATION}

The following is a ist of the symbols most frequently employed in this report and its Appendix:

$A B=$ abnormal load event;

D, L $L_{\text {ANSI, }}$, $W_{\text {ANSI }}=$ Dead load, and live load and wind loads according to ANSI A58.1-1972 [2], respectively;

$F=$ failure event;

$\bar{L}_{S T}, \bar{W}=$ mean short-term live load and wind load, respectively;

$N=$ normal load event;

$P\left(E_{1}\right)=$ probability of occurrence of event $E_{1}$;

$P\left(E_{1} \mid E_{2}\right)=$ probability of occurrence of $E_{1}$ on the condition that event $E_{2}$ occurs;

$P, M=$ axial thrust and moment on bearing wall element;

$p_{f}=$ probability of failure;

$p_{v}, p_{1}, p_{2}=$ vent pressure, magnitude of first and second explosion pressure peak (figure 18), respectively;

$q_{R}, q_{A B}=$ resistance to gas explosion, gas explosion pressure, respectively;

$R^{\prime}, \bar{R}=$ nominal and mean resistance, respectively;

$S_{A B}^{\prime}, \bar{S}_{A B}=$ nominal and mean abnormal load, respectively;

$T=$ time;

$\beta_{f}=$ safety index, defined in section 4.2 ;

$\gamma_{i}, \bar{\gamma}_{i}=$ load factors for load $i$ to be applied to the nominal and mean load value, respectively;

$\delta_{R}, \delta_{i}=$ coefficients of variation in resistance and load $i$, respectively; 
$\lambda=$ mean rate of occurrence of abnormal load;

$\Phi, \Phi^{-1}=$ standard normal probability distribution function and its inverse, respectively;

$\phi, \bar{\phi}=$ resistance factors to be applied to the nominal and mean resistance, respectively;

$\psi=$ vent ratio, defined in the Appendix. 
NOTATION

ABSTRACT.

1. INTRODUCTION.

1.1 Background

1.2 Objective and Scope.

2. PROGRESSIVE COLLAPSE AND ABNORMAL LOADS . . . . . . . . . . . . . . 7

2.1 Basic Concepts. . . . . . . . . . . . . . . . . . . 7

2.2 Abnormal Loading Events. . . . . . . . . . . . . . . 10

2.3 Concepts for Control by Design . . . . . . . . . . . . . . . . 18

3. PROBABILITY OF STRUCTURAL FAILURE UNDER ABNORMAL LOADS -

A CASE STUDY . . . . . . . . . . . . . . . . . . . . . 21

4. DIRECT DESIGN STRATEGIES . . . . . . . . . . . . . . . . . . . . . . . . . 36

4.1 Introduction . . . . . . . . . . . . . . . . . . . . . 36

4.2 Specific Local Resistance Method . . . . . . . . . . . . 36

4.3 Alternate Path Method. . . . . . . . . . . . . . . 4 4 .

4.4 Design Applications in the United States . . . . . . . . . . . 46

5. CONCLUSIONS AND RECOMMENDATIONS . . . . . . . . . . . . . . . . 47

5.1 Summary . . . . . . . . . . . . . . . . . . . . . . . 4 47

5.2 Conclusions and Recommendations . . . . . . . . . . . . . 47

6. ACKNOWLEDGMENTS . . . . . . . . . . . . . . . . . . . . . . . 50

7. REFERENCES . . . . . . . . . . . . . . . . . . . . . . . . . . 51

APPENDIX. GAS EXPLOSION PRESSURES. . . . . . . . . . . . . . . . . . . 56 

DESIGN METHODS FOR REDUCING THE RISK

OF PROGRESSIVE COLLAPSE IN BUILDINGS

by

Edgar V. Leyendecker ${ }^{*}$ and Bruce R. Ellingwood ${ }^{\star}$

\section{ABSTRACT}

A progressive collapse is described as a chain reaction of failures following damage to a relatively small portion of a structure. The damage which results characteristically is out of proportion to the damage which initiated the collapse. The basic concepts associated with progressive collapse are described and the background leading to the concepts is summarized. Possible causes of progressive collapse are discussed, with concentration on abnormal events which have a low probability of occurrence but may have catastrophic consequences. A case study of the probability of structural failure as a consequence of one type of abnormal load (a gas explosion) shows that these probabilities exceed levels generally considered acceptable to engineers.

Direct design strategies for reducing progressive collapse are described as (1) the Alternate Path Method and (2) the Specific Local Resistance Method. Equations for load combinations, including appropriate load factors, are presented for each design method. The advantages and disadvantages of each approach are described and it is concluded that the alternate path method affords the designer more flexibility. Although the design strategies are applicable to any type of structure at any time in its life cycle, this report provides detailed recommendations for completed buildings.

Key words: Abnormal loading; alternate path; building code; design criteria; probability; progressive collapse; reliability; structural engineering; uncertainty.

ॠ Dr. Leyendecker and Dr. Ellingwood are Research Structural Engineers in the Structures Section of the Structures, Materials, and Safety Division of the National Bureau of Standards' Center for Building Technology. 


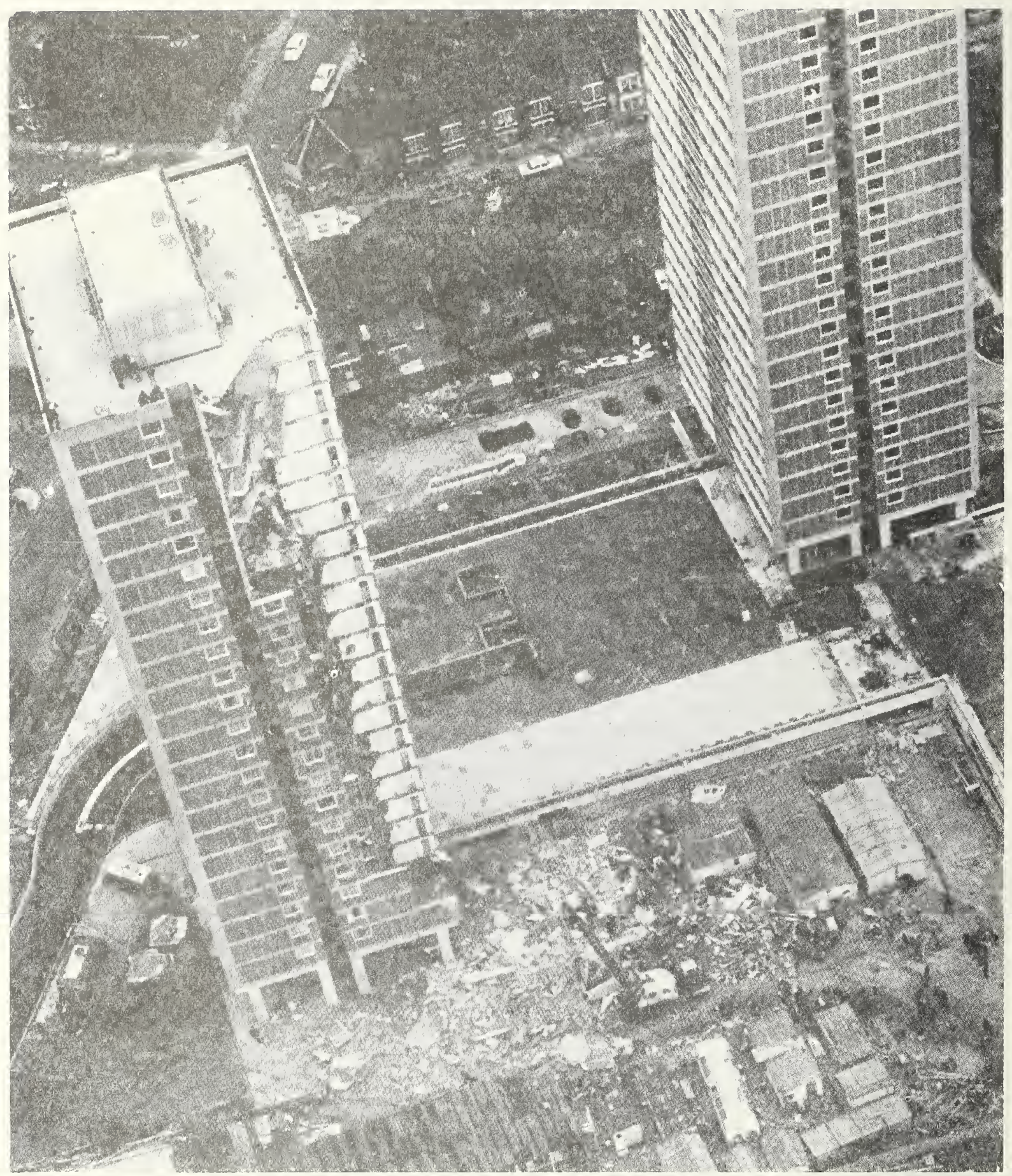

Figure 1 Ronan Point Apartment Building After the Collapse, with a Second Identical Building in the Background. (Courtesy of London Express News and Feature Services). 


\subsection{Background}

In 1968 the newly occupied Ronan Point apartment building, located in London, England, underwent a partial "house of cards" collapse (figure 1). The building consisted of 22 stories of apartments built using precast concrete panels which rested on a cast-in-place podium containing garages and a car deck [25] $]^{1}$. The collapse followed a gas explosion in the kitchen of an apartment on the 18th floor which blew out an exterior wall panel. The resulting loss of support caused a chain reaction of collapse upwards to the roof. The collapse also progressed almost to the ground as debris from above fell on successive floors below. This type of chain reaction or propagation of failure following damage to a relatively small portion of a structure has been termed "progressive collapse." Since the gas explosion which initiated the collapse was a loading event not usually considered in building design, it was termed an abnormal loading.

The subsequent report [25] of the Commission of Inquiry concluded, among other findings, that although the concrete panel structure met applicable building regulations it was not "an acceptable building." The Commission focussed on the lack of load redistribution capability, or what it termed "alternate paths," in the building. In general, the Commission expressed its belief that reinforced-concrete and steel-framed structures possessed such redundancy, as demonstrated by their behavior during World War II bombings (figure 2). On the other hand the commission pointed out that it was not necessarily a natural concomitant that panel structures should lack alternate paths which could provide protection against progressive collapse. This point was illustrated by the behavior of a concrete panel building in Algeria shown in figure 3 which lost several panels due to a bomb explosion but did not collapse.

Subsequent to the report on the Ronan Point collapse, the Ministry of Housing and Local Government issued Circular 62/68 entitled "Flats Constructed with Precast Concrete Panels. Appraisal and Strengthening of Existing Blocks: Design of New Blocks [18]." In addition to other items, the circular required that multistory buildings be designed to provide either an alternate load path in the event of the loss of a single critical member or sufficient local resistance to withstand the effects of a 5 psi $\left(34 \mathrm{kN} / \mathrm{m}^{2}\right)$ pressure. The specified pressure was based on a gas-type explosion, although this was not stated in the document. The intent of the $5 \mathrm{psi}\left(34 \mathrm{kN} / \mathrm{m}^{2}\right)$ design pressure was to prevent the initial failure needed to trigger a progressive collapse, while the intent of the alternate path approach was to allow the initial failure but confine its effects to prevent progressive collapse. An amendment

Tumbers in brackets refer to references 1 isted at the end of the report. 


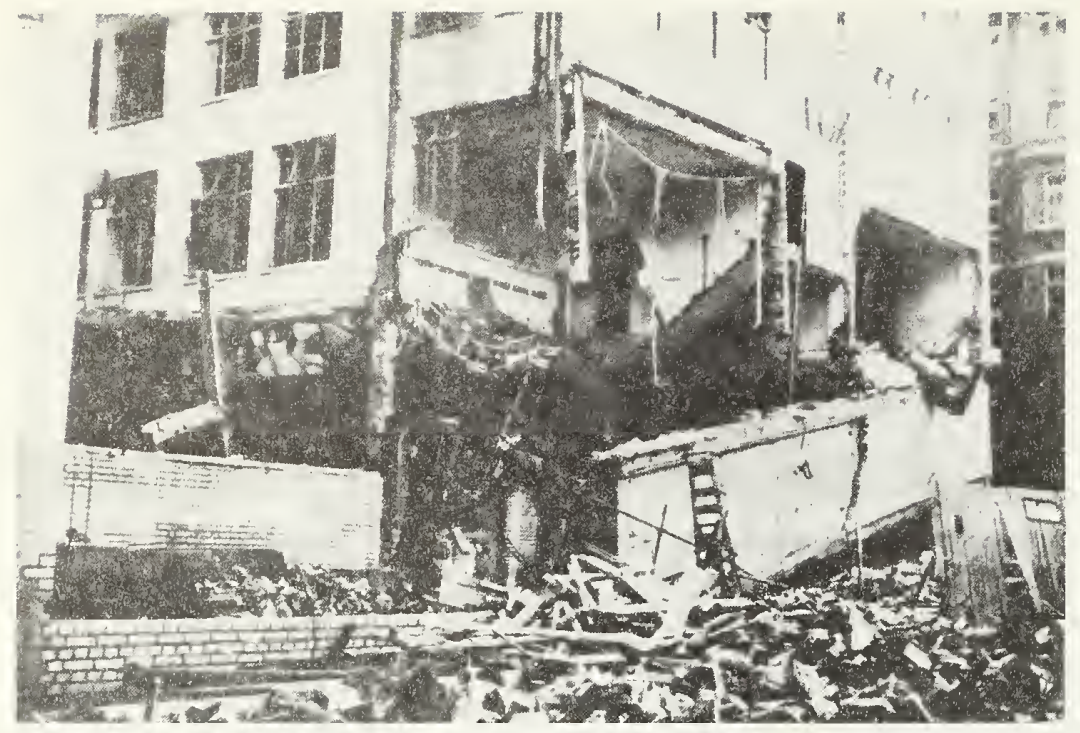

Figure 2 Detail of a Seven-Story-Steel-Framed

Building After a Wartime (World War II) Bomb.

Figure 3 Concrete Panel Building in ATgeria Damaged by an Explosion.

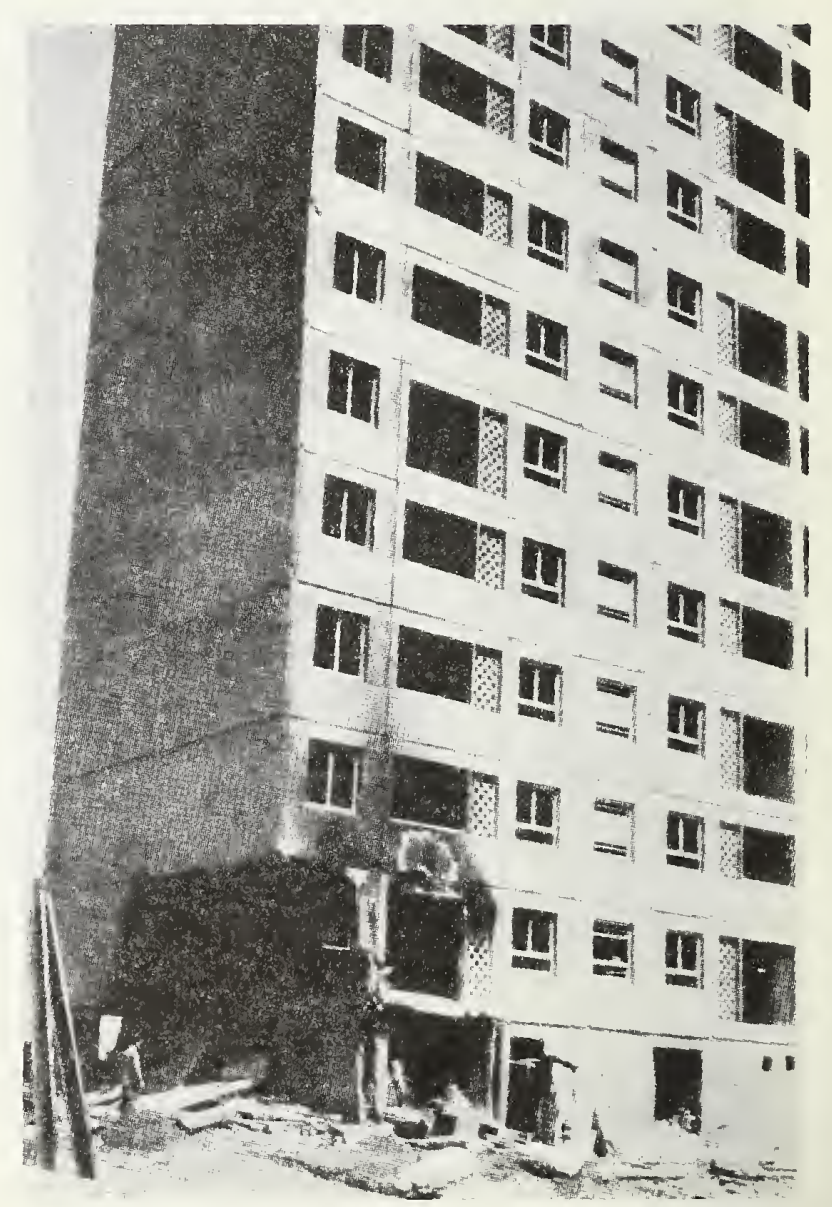


to the British building regulations was later proposed [47] which was similar to Circular 62/68 [18] and was finally adopted as the "Fifth Amendment" [55] to the regulations.

In the United Kingdom (U.K.) the Ronan Point collapse aroused widespread concern as a social problem involving life safety [6]. However, the "Fifth Amendment" received considerable criticism not only in the U.K. but elsewhere. As a matter of philosophy, it was claimed that since a collapse was a collapse, a progressive type of failure should not be singled out for attention in the building regulations [6]. Proponents of this position argued that a safe building was achieved not by a set of restrictive building regulations, but only when an engineer, architect, and builder unite to make it safe $[6,7]$. The local resistance approach was criticized on the basis of the lack of information about the dynamic effect of an abnormal load on a structure and, due to this insufficient knowledge, specification of a static pressure of $5 \mathrm{psi}\left(34 \mathrm{kN} / \mathrm{m}^{2}\right)$ was considered unjustified $[4,7,31,32]$. Moreover, it was argued that the required pressure would not necessarily protect against other abnormal events such as vehicular collisions [29]. The alternate path approach was thought to be too complex $[31,32]$ as well as $i 110 \mathrm{gica} 1$, since more than one critical 10adcarrying member could be removed by an abnormal event such as an explosion [29]. Finally the regulations were criticized for being implemented without knowing the effect on the cost of building construction $[6,38]$.

Despeyroux [14] pointed out that the 1967 Comite European du Beton (CEB) Recommendations [49] addressed the possibility that panel structures might behave as a "house of cards" as is indicated in the following translation [25].

General Organisation of the Structure

One can hardly over-emphasise the absolute necessity of effectively joining the various components of the structure together in order to obviate any possible tendency for it to behave like a 'house of cards' and of organising the structure accordingly. In this respect it would appear to be of major importance to install mechanically continuous steel ties interconnecting opposite walls or facades and providing safeguards for all the vertical panels'.

Both Despeyroux [14] and Saillard [52] regretted that the official Ronan Point report did not specifically point out that the collapsed building violated these CEB principles. Saillard further observed that the Algerian building cited in the Ronan Point report and shown in figure 3 in fact met the CEB requirements and survived a severe explosion. Like some of their British counterparts, they also thought the $5 \mathrm{psi}\left(34 \mathrm{kN} / \mathrm{m}^{2}\right)$ pressure was too high and the alternate path approach was too complex. Robinson [50] also suggested that the alternate 
path approach was too severe a requirement since engineers have long designed statically determinate structures that have no alternate path.

Firnkas [20] expressed the opinion that the Ronan Point structure would not have been acceptable in the United States since the design of concrete panel structures in the U.S. was considerably more conservative at that time than in the U.K. Later, Popoff [45,46] argued for the adoption of design principles similar to those used in earthquake design rather than the adoption of rules such as contained in the "Fifth Amendment." This approach would consist primarily of good detailing as well as minimum strength and continuity provisions.

Despite the above objections, the Ronan Point incident has affected the building regulations of many countries. Burnett [10] has documented and compared the non-U.S. regulations. In North America the Canadian Code has incorporated a progressive collapse design requirement [41,42]. However, there is 1 imited guidance in current U.S. codes and standards with regard to progressive collapse. The 1972 American National Standards Institute's Standard (ANSI) A58.1 [2] contains merely a warning on the hazards associated with progressive collapse. The City of New York amended its building code in 1973 [51] to require that progressive collapse resistance be provided by either the local resistance or the alternate path method.

Currently the subject of progressive collapse is under study by committees of the American Concrete Institute and the Prestressed concrete Institute. It is anticipated that the ANSI A58.1 committee will soon appoint a group to study possible standard provisions. The Department of Housing and Urban Development (HUD) has also expressed concern with progressive collapse, and this concern has resulted in both sponsored research at the National Bureau of Standards and the Portland Cement Association and a draft document [57] for guidance in design.

\subsection{Objective and Scope}

The objectives of this report are to describe general approaches to designing structures to resist progressive collapse. Data which support the recommendations are included in the report.

The design recommendations contained herein are considered applicable to al1 types of construction but are intended for a structure in the completed state as opposed to one under construction. Although certain portions of the report should be useful in deriving similar guidelines for buildings under construction, the development of such guidelines was considered to be outside the scope of this study. 


\section{PROGRESSIVE COLLAPSE AND ABNORMAL LOADS}

\subsection{Basic Concepts}

The progressive type of collapse consists of (1) an event which results in (2) failure of one or more primary structural elements followed by (3) a chain reaction of failures. The second and third stages of this process are shown schematically in figures $4 a$ and $4 b$ (modified after Dragosavic [15!), respectively, for the Ronan Point collapse.

The sequence of events that occurs during a collapse (progressive or otherwise) is shown in figure 5. This diagram will be discussed using several examples.

(a) Ronan Point - Following the initial wall panel failure, the loads redistributed. However, since adjacent members lacked continuity and strength, additional members failed. Since the building had not totally collapsed, the loads redistributed again. The cycle continued until the failure zone isolated itself. This chain reaction of failures was considered out of proportion to the initial failure caused by the gas explosion and was termed a "progressive collapse."

(b) Algeria (figure 3) - Following the initial local failures, the load redistributed. Since, this building had both sufficient strength and continuity that the redistributed loads could be supported by surrounding elements, the collapse was contained.

(c) Hypothetical examples - Consider a building supported by one column at the ground story. A loading event that causes failure of that column results in the collapse of the entire structure. Since there is no chain reaction of fajlures, the collapse is not termed a progressive collapse.

If a building is supported by four columns, the destruction of two (or more) of these columns will cause redistribution of loads. The surrounding elements probably will be unable to carry the redistributed loads because the destroyed elements constitute such a large portion of the support system, and a chain reaction of failures will occur. However, this failure is termed a ceneral rather than a progressive collapse because the initial damade is more than a smal1 portion of the structure. 


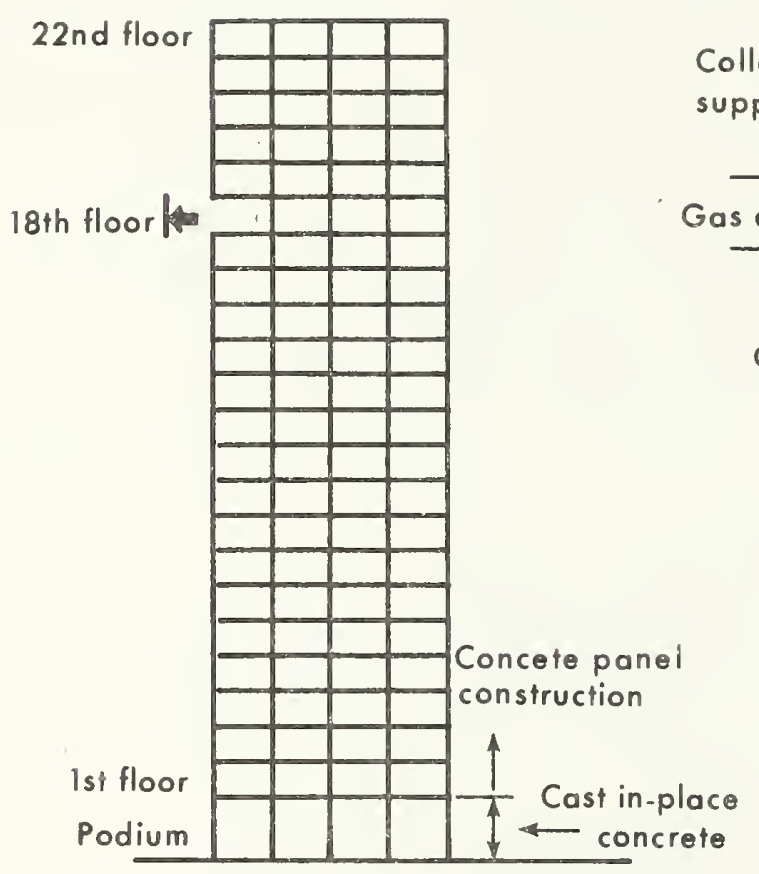

(a) Failure of primary structural element

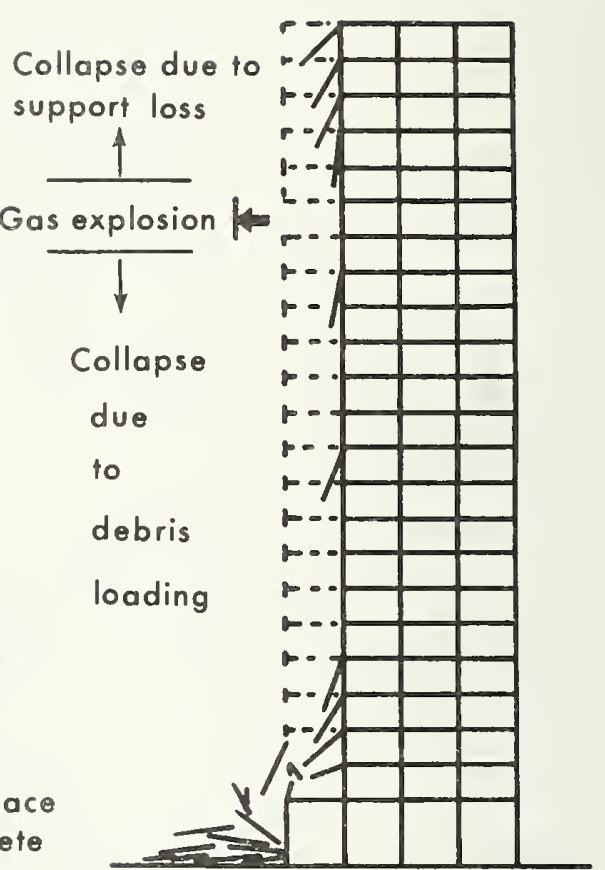

(b) Chain reaction of failures

Figure 4 Schematic of the Ronan Point Collapse, Modified After Dragosavic (15). 


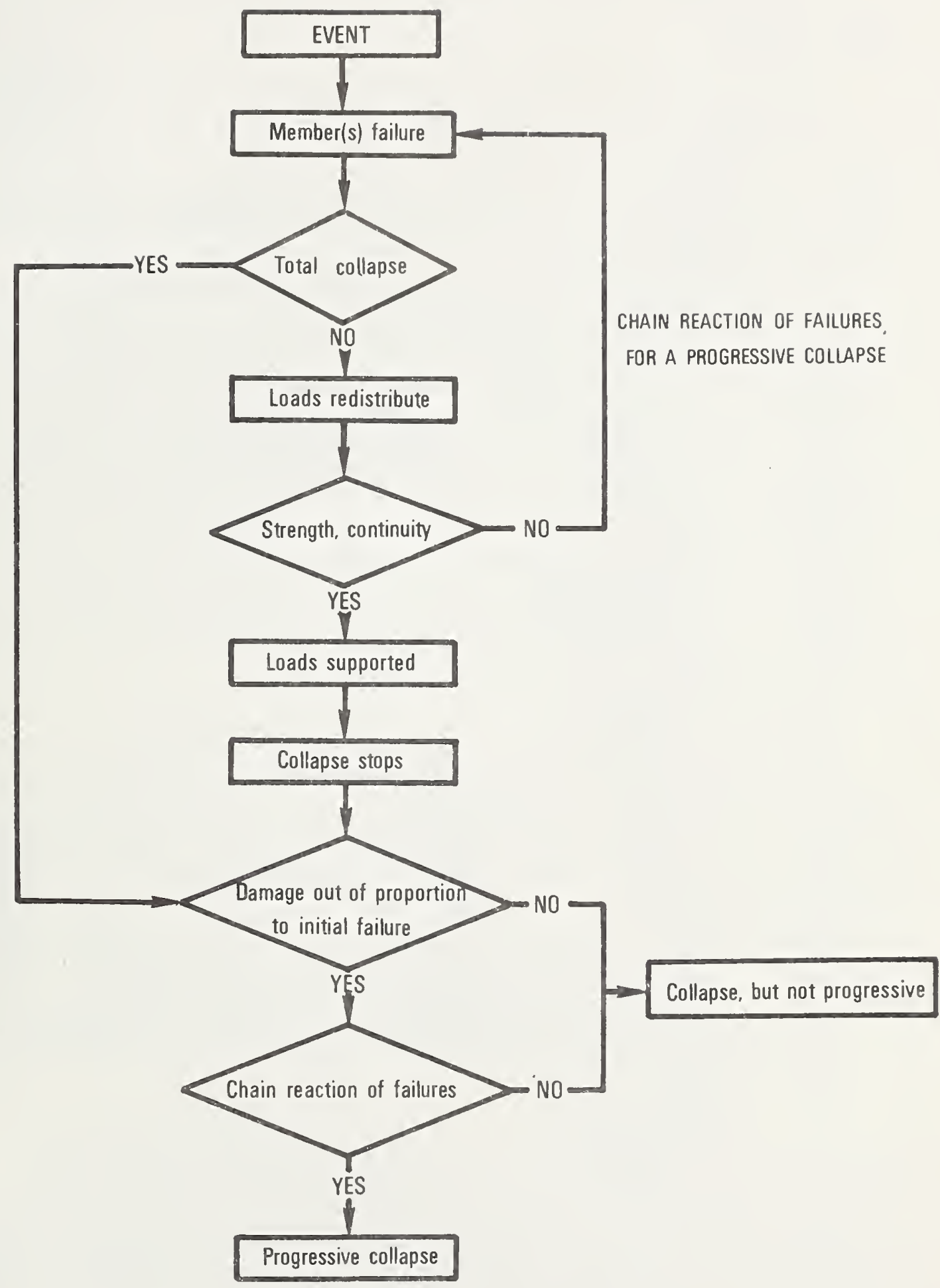

Figure 5 Sequence of Events During Structural Collapse. 
The preceding discussion demonstrates the definition of progressive collapse, namely:

a chain reaction or propagation of failures folzowing damage to

a relatively small portion of a structure.

This is a qualitative definition since the meaning of "a relatively small portion of a structure "requires judgement and depends on the damage level society is willing to accept.

In order to determine how serious a problem progressive collapses might be, Allen and Schriever [1] conducted a survey to determine their frequency of occurrence. They used two news sources - the Engineering News Record (ENR) from 1968 to 1972 and newspaper clippings from Canadian newspapers from 1962 to 1972. The results of the Allen and Schriever survey are shown in figure 6 . Based upon the ENR data, an estimate of 5-1/2 progressive collapses per year was obtained. This is about 20 percent of the total of 110 collapses recorded by ENR during the four-year survey period. The newspaper survey over a tenyear period resulted in a slightly larger annual estimate of progressive collapses, 7-1/2 per year, constituting about 15 percent of the total number of collapses. It may be concluded that progressive collapse is a serious enough problem to warrant consideration in design.

\subsection{Abnormal Loading Events}

Buildings are routinely designed for dead, live, snow, wind, and earthquake loads. However, there are those loads which, although they may have a low probability of occurrence relative to common structural design loads, may precipitate catastrophic structural failure if they occur. These are termed abnormal loading events.

Somes [53] has attempted to classify the various abnormal loadings as fo110ws:

A. Violent Change in Air Pressure

B. Accidental Impact

C. Faulty Practice

D. Foundation Failure

Burnett [9] has developed a more extensive classification system.

There have been a number of efforts to gather data on abnormal events subsequent to the Ronan Point Collapse $[1,9,22,24,34,35,53,60]$. The report by Leyendecker and Burnett [34] contains data on the following types of abnormal events in the United States:

- Gas-Related Explosions

- Bomb Explosions

o Motor Vehicle Collision with Buildings 

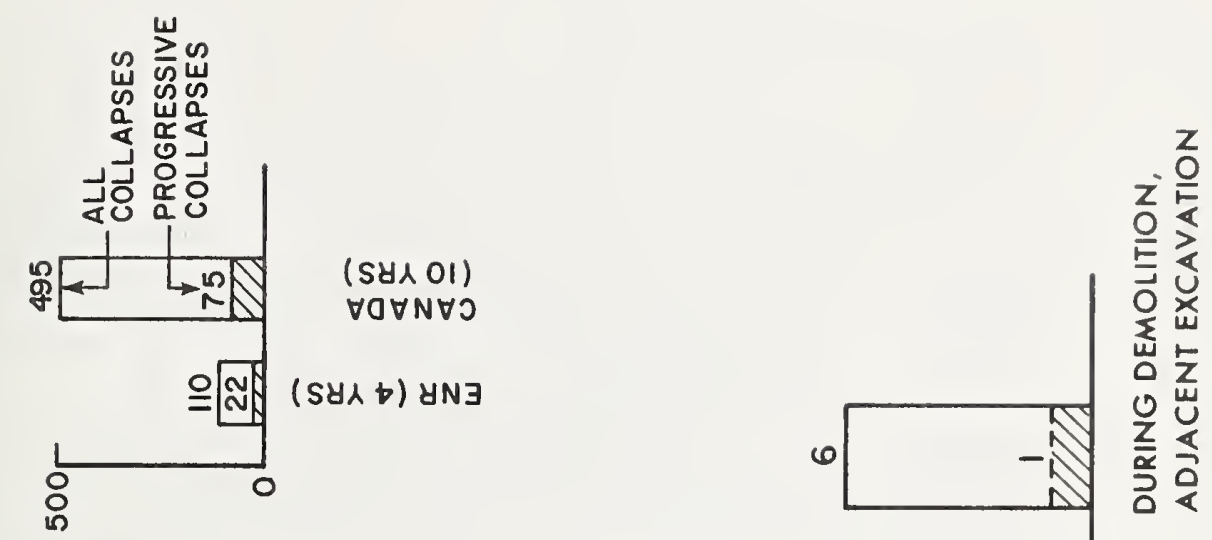

$\perp$ $\forall d W I O \perp \exists \cap 0$

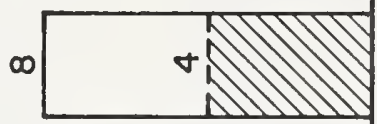

NOISO7dX $0 \perp \exists n 0$

定

0 웅

逢它

엉

通出

yoyy3 N9ISヨO

崖采

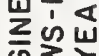

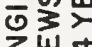

$\sum_{\text {W }}$

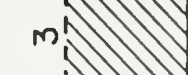

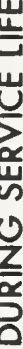

0
$\vdots$
0
$\frac{0}{0}$
0

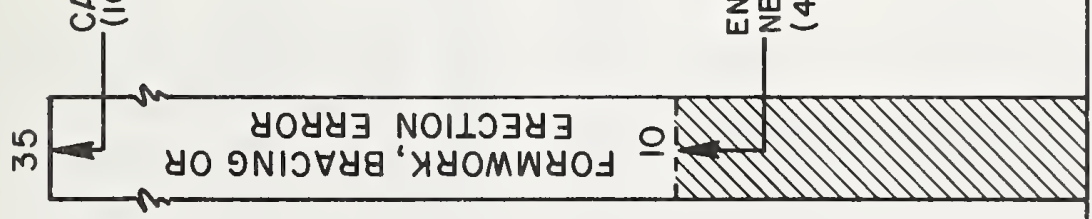

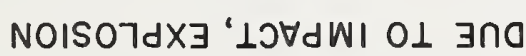

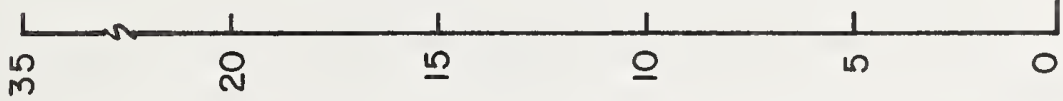

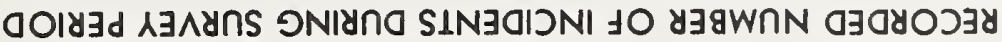


- Sonic Boom

- Aircraft Collision with Buildings

o Explosion of Hazardous Materials

These loads fall in Somes' category A and B. The purpose of their study was to assess the risk of such loadings in completed residential buildings. The list of loadings was not considered exhaustive; however, based on earlier work by Allen and Schriever [1] and Ligtenberg [35] these loads were considered as plausible sources of the initial failure which might lead to progressive collapse.

It was concluded [34] that, of the abnormal loads listed above, only the gas explosion, bomb explosion, and vehicular collision constitute a problem for buildings. The annual data for these loads are summarized in figure 7 . Both the total number of incidents and the annual frequency per million dwelling units (based on a 1970 total of 67.7 million dwelling units) are shown. The damage levels described in the figure are based on the following definitions:

(1) Total incidents - All incidents involving a particular abnormal 1 oad.

(2) Intermediate damage - Damage between $\$ 1000$ and $\$ 10,000$ for gas explosions: $\$ 1000$ and $\$ 5000$ vehicular collision, or described as intermediate for bomb explosions. This level implies fairly extensive damage such as walls blown down.

(3) Severe damage - Damage in excess of $\$ 10,000$ for gas explosions; $\$ 5000$ for vehicular collision; or described as severe for bomb explosions. This level implies extensive structural damage, such as dwelling unit destroyed.

These definitions, which involve some arbitrary judgements, were adopted because of the limitations on the available data. For example, the number of incidents causing damage in excess of a prescribed legvel (as measured in dollars) or a brief description of damage is all that is usually provided. There is rarely complete information on the type or number of structures affected or an adequate description of their damage. There are also no available U.S. data which provide a correlation between a prescribed damage level and a corresponding damage loss in dollars. Finally, there are no data on the load characteristics of the actual events. However, it is interesting to note that Taylor and Alexander [60] collected data in which some 122 gas explosions caused damage judged as significant (similar to the category of severe used in this report) with an estimated total loss of repair $£ 500,000$. This is an average of $\$ 4100$ per incident or about $\$ 10,200$ (at an exchange rate of $\$ 2.50$ ) in terms of the 1971 - 1972 collection period. Although circumstances differ 


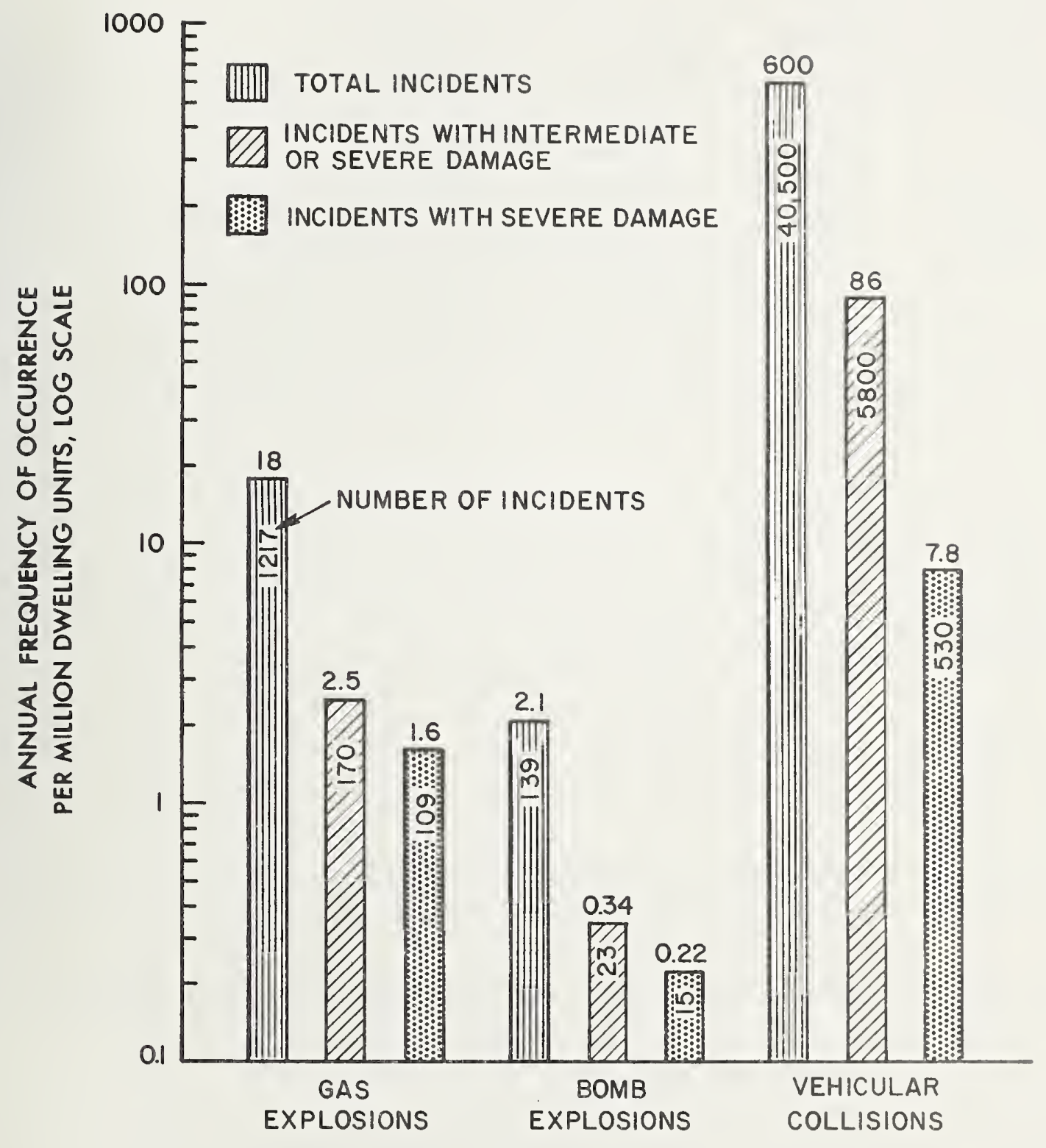

Figure 7 Summary of Annual Probabilities of Abnormal Loadings for 1970 
considerably, this lends further substance to the judgments made above which correlate damage to dollar amounts.

The data for the gas explosion, bomb explosion, and vehicular collision may be discussed in terms of probability theory. The probability of structural failure due to abnormal loads, $P(F)_{A B}$, may be stated as

$$
P(F)_{A B}=P(F \mid A B) \times P(A B)
$$

where

$$
\begin{aligned}
& P(F \mid A B)=\text { Probability of failure given an abnormal load event; } \\
& P(A B)=\text { Probability of occurrence of an abnormal load event. }
\end{aligned}
$$

The probability of occurrence of an abnormal load event, $P(A B)$, is independent of any particular type of bujlding construction or procedure used in design but may depend on the occupancy. On the other hand, the probability of failure given an event, $P(F \mid A B)$, is a function of building type as well as the particular codes and standards used in its design and construction.

Equation 1 assists in the interpretation of the annual frequencies shown in figure 7. The probability of occurrence, $P(A B)$, is readily obtained from the data in the figure. Since data on $P(F \mid A B)$ and $P(F)_{A B}$ are not available, data have been presented instead in a form resulting in the probability of damage above a prescribed leve1, $P(D)_{p}$,

$$
P(D)_{p}=P\left(D_{p} \mid A B\right) \times P(A B)
$$

where

$$
\begin{aligned}
P\left(D_{p} \mid A B\right)= & \text { Probability of damage above a prescribed level, given an } \\
& \text { abnormal load event; } \\
P(A B)= & \text { Probability of occurrence of an abnormal load event; } \\
P= & \begin{array}{l}
\text { Subscript indicating the prescribed damage level, e.g. } \\
\text { intermediate or severe. }
\end{array}
\end{aligned}
$$

The terms $P(D)_{p}$ and $P(A B)$ are obtainable from the data in figure 7 and $P\left(D_{p} \mid A B\right)$ may be computed using equation 2 rewritten as

$$
P\left(D_{p} \mid A B\right)=\frac{P(D)_{p}}{P(A B)}
$$


Using this equation, values for $P\left(D_{p} \mid A B\right)$ were computed and are shown in table 1.

Table 1. Calculated Estimates of $P\left(D_{p} \mid A B\right)$

\begin{tabular}{|c|c|c|c|c|}
\hline \multirow[b]{2}{*}{$\begin{array}{l}\text { Abnormal } \\
\text { Loading }\end{array}$} & \multirow[b]{2}{*}{$P(A B)$} & \multicolumn{2}{|c|}{$P(D)_{p}$} & Calculated $P\left(D_{p} \mid A B\right)$ \\
\hline & & $\begin{array}{l}\text { Based on } \\
\text { Intermediate } \\
\quad \text { Damage }\end{array}$ & $\begin{array}{l}\text { Based on } \\
\text { Severe Damage }\end{array}$ & $\begin{array}{l}\text { Based on } \\
\text { Intermediate Based On } \\
\text { Damage Severe Damage }\end{array}$ \\
\hline Gas. Expl. & $18 \times 10^{-6}$ & $2.5 \times 10^{-6}$ & $1.6 \times 10^{-6}$ & 0.089 \\
\hline Bomb Expl. & $2.1 \times 10^{-6}$ & $0.34 \times 10^{-6}$ & $0.22 \times 10^{-6}$ & 0.16 \\
\hline Veh. Coll. & $600 \times 10^{-6}$ & $86.0 \times 10^{-6}$ & $7.8 \times 10^{-6}$ & 0.013 \\
\hline
\end{tabular}

NOTE: The probabilities listed are per dwelling unit.

Based on the data in figure 7 and table 1 , the following conclusions were made:

1. Gas explosions occur with an annual frequency of 18 events per million dwelling units. Among all construction types there is an annual frequency of 1.6 events per million dwelling units causing severe damage. Based upon the assumption that severe damage is equivalent to structural failure there is a 9 percent probability of element fajlure, given that the event occurs.

2. Bomb explosions occur with an annual frequency of 2.1 events per million dwelling units. Among all construction types there is an annual frequency of 0.22 events per million dwelling units causing severe damage. Based on the assumption that severe damage is equivalent to structural failure, there is an 11 percent probability of element failure given that the event occurs.

3. Vehicular collisions with buildings occur with an annual frequency of 600 events per million dwelling units. Among all construction types there is an annual frequency of 7.8 events per million dwelling units causing severe damage. Based on the assumption that severe damage is equivalent to structural failure, there is a 1 percent probability of element failure, given that the event occurs.

Since abnormal loads are quite rare and reasonably uniformly distributed in time, it may be assumed that their occurrence is a poisson process. If $N(T)$ is the number of abnormal loads occurring in time interval $T$, then

$$
P[N(T)=n]=\frac{(\lambda T)^{n} e^{-\lambda T}}{n !}
$$


where $\lambda$ is the mean rate of occurrence of abnormal loads; for small values of $\lambda, \lambda=P(A B)$. Denoting $p_{f}=P(F \mid A B)$, the number of failed elements $N_{F}$ in $T$ is also a Poisson process with the same probability law as equation 3 , replacing $\lambda$ with $\lambda p_{f}$. The probability of one or more structural elements failing from gas explosions is then $P\left[N_{F}(T)>0\right] \approx p_{f} \lambda T$. With lifetime $T$ typically about 60 years, $\lambda=18 \times 10^{-6}$, and assuming that $P\left(D_{\text {severe }} \mid A B\right) \approx$ $P(F \mid A B) \approx 0.1$ from table 1 , the probability of failure due to abnormal load during the life of the structure is about $1.1 \times 10^{-4}$. This compares unfavorably with the probability of failure under normal loads, which is of the order of $10^{-5}$ or less [17]. It should be noted that the statistics do not differentiate between building types or the regulations used in their design.

Depending upon the type of abnormal loading event, the probability of an event occurking in a building is likely to increase with the building size. In the case of the gas or bomb explosion the statistics summarized in figure 7 are independent of the location of a unit in a building. Thus the probability of occurrence for either such event increases in proportion with the number of units in a building. In the case of the vehicular collision, it is assumed that only the ground story is accessible to a vehicle and hence the probability of collision is proportional only to the number of units at ground 1 evel.

The variation of the probability with building size for the category of severe abnormal loading events is shown in figure 8 . The effect of building size on the probability of an event is shown by plotting probability versus the number of dwelling units (the probabilities were obtained by multiplying the appropriate data in figure 7 by the number of residential units). Auxiliary axes are provided to indicate the number of stories when there are 5, 10, 15 or 20 dwelling units per story. Since the data for vehicular collisions were taken proportional to the number of units at the ground level rather than the number of units in the building, comparisons can only be made at discrete points. Thus, the horizontal lines shown in figure 8 which indicate probability of severe collision, are maximums for buildings with the number of units per story shown encircled in the figure. For instance, assuming 10 units/story and reading the appropriate axis, it may be seen that the probability for a gas explosion exceeds a vehicular collision for buildings greater than about 5 stories in height, issuming a constant number of units per story. It can be shown by reading the appropriate axis that this height of 5 stories is independent of the number of units per story. Similarly bomb explosions exceed vehicular collisions for buildings over 35 stories in height, assuming a constant number of units per story. This height is also independent of the number of units per story.

A data point for an explosion in a building the size of Ronan Point (see section 1) is shown based on an annual frequency of 2.2 severe gas-related explosions per million dwelling units (Great Britain data, see reference [34]) 


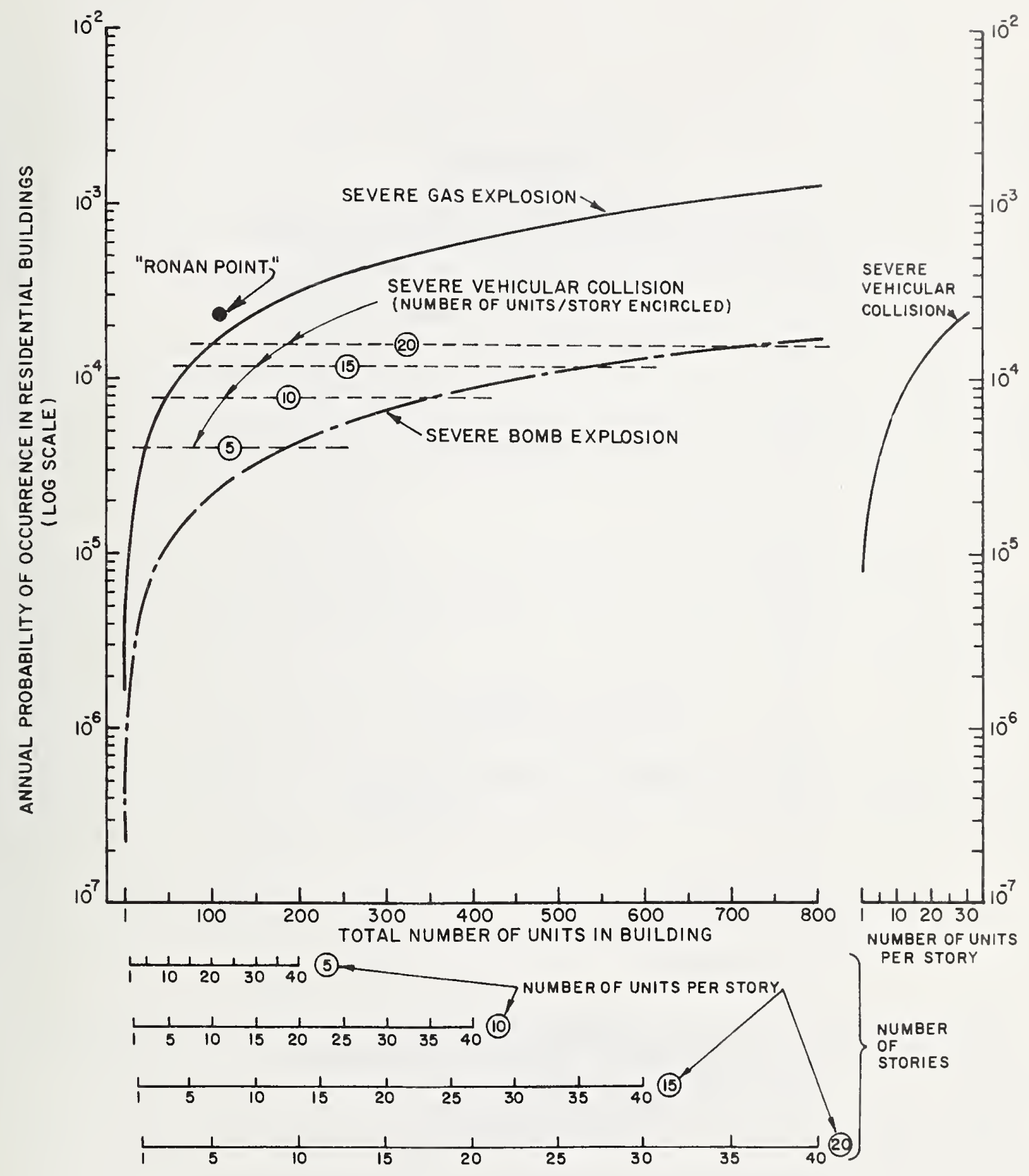

Figure 8 Variation of Probability of Severe Abnormal Loadings with Increasing Size of Building. 
and a 22-story high building with 5 dwelling units per story. Note that the point is very close to the U.S. data for explosions causing severe damage.

The probabilities of these three abnormal loading events increase with building size. For the case of severe damage, the gas explosion event approaches an annual probability of $1 \times 10^{-3}$, exceeds the bomb explosion event by an order of magnitude, and is greater than that for vehicular collisions for buildings in excess of five stories in height. In addition, there are sufficient data available to develop a design load on a rational basis. Therefore the gas explosion would appear to be the most appropriate load to use in situations where one normative abnormal load must be specified in order to determine possible structural damage or needed resistance.

No data on load magnitudes were available for the U.S. statistics used in the previous section. In all of the reports previously cited, only Taylor and Alexander [60] reported load data. They evaluated 122 gas explosions judged as severe. Each of the incidents was investigated and a low and high estimate for pressure was assigned based on characteristics of physical damage. Their results are shown in figure 9.

As expected, "1arge" peak pressures occur only rarely. In particular, the pressure of $5 \mathrm{psi}\left(34 \mathrm{kN} / \mathrm{m}^{2}\right)$ which is mentioned frequently in progressive collapse literature was exceeded only four times (at most) in the two years of their survey.

2.3 Concepts for Reducing the Risk of Progressive Collapse

Conceptually the approaches for reducing the risk of a progressive or chain reaction type of failure may be categorized as. (similar to Burnett [10]):

\section{Event Control, \\ 2. Direct Design, or \\ 3. Indirect Design.}

Event Control refers to reducing the risk of progressive collapse by such means as (a) eliminating the event, e.g., avoiding the use of gas in a building, (b) protecting against the event, e.g., erecting a barrier around a column to prevent vehicular collision, or (c) reducing the effect of the event, e.g., provide explosion venting to reduce pressure buildup. This approach does not increase the resistance of a structure to progressive collapse. For instance, the Ronan Point building was susceptible to progressive collapse since the structure was built much like a house of cards [25]. The lack of inherent resistance to such collapse would have been unchanged even if gas service had not been supplied to the building. This approach is also dependent on factors that are outside the control of the designer and thus is not considered a practical means of reducing the risk of progressive col1 apse. 


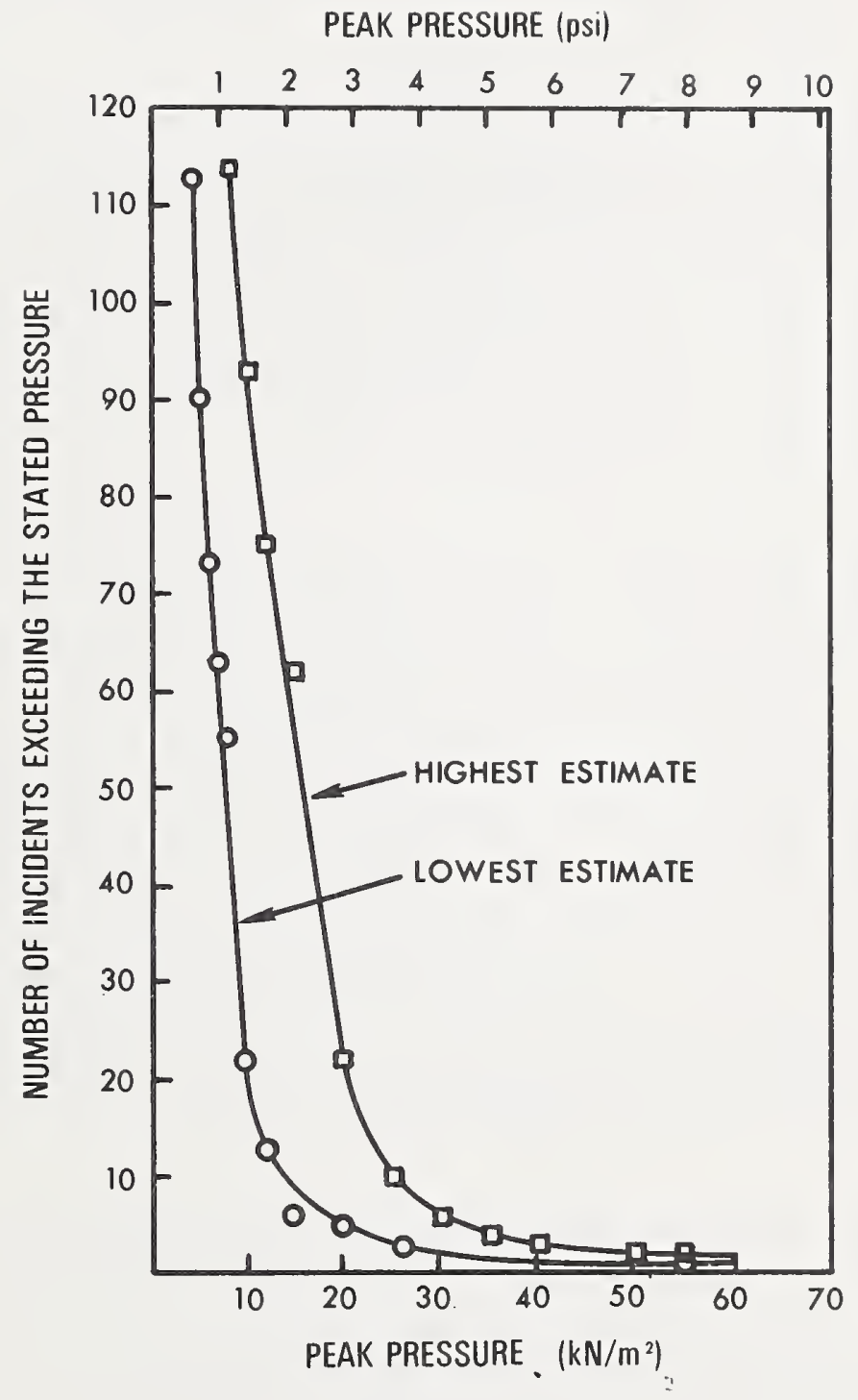

Figure 9 Frequency-Severity Curve for the Significant Events in Taylor and Alexander's Survey. 
The remaining two approaches are within the control of a designer. These approaches should satisfy the following performance requirement:

\begin{abstract}
Structures should be designed so that if local damage occurs, there is a reasonable probability that the structure as a whole wizl not be damaged to an extent disproportionate to the original cause of the local damage.
\end{abstract}

The requirement expresses the need for structures to be inherently capable of limiting the spread of local damage regardless of the cause. This does not mean an initial failure should necessarily be prevented but rather the structure should be capable of absorbing the damage, regardless of the reason for the initiating event. The statement applies equally to all construction, regardless of materials. Although some materials may require more care than others, it should be noted that progressive failures have been documented [24,59] in most construction materials.

Direct Design refers to explicit consideration of resistance to progressive collapse during the design process. The two basic design means are (1) the Alternate Path Method or (2) the Specific Local Resistance Method. The first method allows local failure to occur but seeks to provide alternate load paths so that the damage is absorbed and major collapse is averted. The second method seeks to provide sufficient strength to resist an event although some damage may occur. This method may, as a consequence of developing strength in critical elements and joints, also result in sufficient strength and continuity to provide alternate paths. However, it cannot be assumed that the provision of specific local resistance will result in an alternate path. It should also be noted that the two methods can be used in conjunction with each other in a particular structure. This report develops guidelines which may be used in the two Direct Design methods described above.

Indirect Design refers to consideration of resistance to progressive collapse by specifying minimum ?evels of strength, continuity, and ductility. The latter approach has been advocated by many [5,19,39,45,46]. McGuire [39] refers to this approach as General Structural Integrity. Fintel and Schulz [19] have also used the latter phrase to describe this approach. However, they have modified the definition by also defining General Structural Integrity as the ability to bridge over local failure (i.e. possessing alternate paths). This Indirect Design approach cannot always be assumed to result in the ability to bridge over local failure since such a method cannot be general enough to apply to every possible structural configuration.

The provision of General Structural Integrity (as defined by McGuire) is attractive because of its simplicity and ease of use. However, the 
development of the minimum levels of strength, continuity, and ductility will usually require laboratory investigation and is thus outside the scope of this report.

Application of the two design methods is illustrated in figure 10. The performance statement contained in the general code provisions states what is expected of the designer. The Direct Design method provides guidelines for achieving the required performance. For simplicity it is desirable that requirements for General Structural Integrity be included in the specific materials portion of the code (in general these requirements are yet to be determined). These provisions would be deemed to satisfy the performance statement unless the building is unusual. The designer would then use the Direct Design method to satisfy the performance requirement.

The definition of an unusual structure is not precise. The meaning implied here is a structure which does not have a history of performance, contains new materials or structural concepts or, in short, a structure departing from the type envisioned in formulating the specific material oriented design requirements.

By virtue of the normal design process, a certain amount of strength and continuity is provided which is also available to resist the abnormal load. Thus, normal design may, at the same time, provide protection against abnormal events, and indeed this has been demonstrated in the past on a number of occasions (figures 2 and 3 ). However, since codes, standards, and building materials, as well as construction techniques change with time, it cannot be assumed that this protection will always be provided in the future. Therefore it is considered necessary that progressive collapse provisions be included in general design requirements.

\section{PROBABILITY OF STRUCTURAL FAILURE UNDER ABNORMAL LOADS - A CASE STUDY}

As discussed previously, vulnerability to abnormal loads is a special problem in structures in which 1 imited continuity between structural elements exists [53]. In such instances special precautions must be taken at the planning stages of design to insure that in the unlikely event of an abnormal load occurrence, the resulting structural damage will remain localized. As the abnormal load as well as factors governing the element resistance are random in nature, specific design criteria for the above purpose should have a probabilistic basis.

In this section initial failure risks for an existing structural design subjected to a gas explosion are evaluated. This is done both to compare such risks with others tacitly dealt with by the engineering profession and society in general, and to aid in establishing target reliability levels 


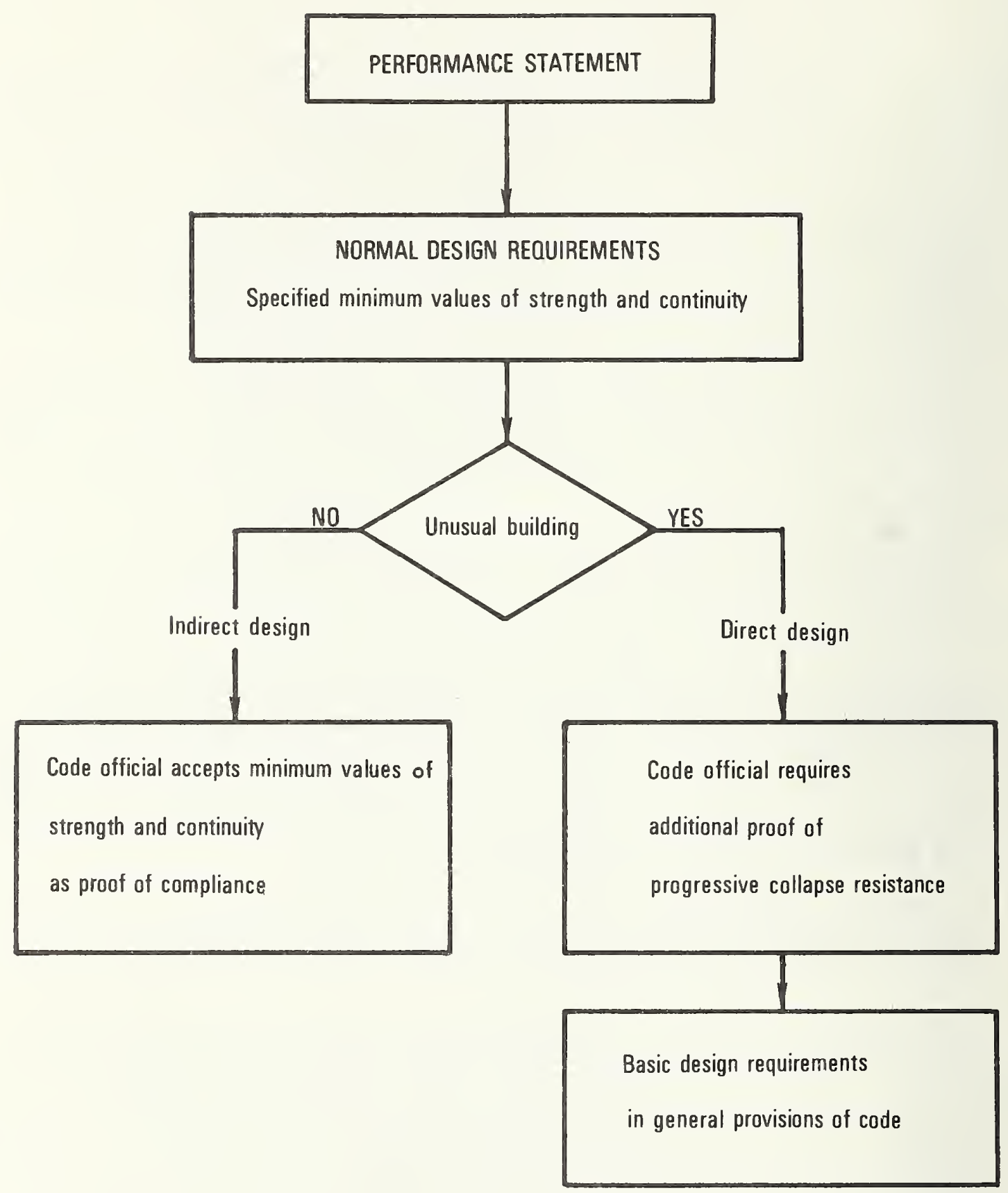

Figure 10 Design Procedure. 
upon which abnormal load design criteria can be based. An eight-story nonreinforced brick masonry residential building has been selected for this case study because it is typical of a structure where limited continuity may exist even when properly designed according to current building codes, and because such structures represent a significant proportion of the building population in the United States. This building was also considered by McGuire and Leyendecker [40] in a previous deterministic study.

Figure 11 is an elevation view and half section of the building studied. The walls and piers are lettered for identification. In the part investigated, the brick cross wall spacing is $92 \mathrm{ft}(28.0 \mathrm{~m})$. Floor construction is of 8-in $(20.3 \mathrm{~cm})$ deep, one-way, prestressed, precast concrete planks. They bear on the corridor walls and on the exterior walls, piers, and intels. There are no longitudinal ties (floor reinforcement parallel to the planes of the walls) between the ends of the planks. The brick walls and piers are reinforced only at the floor-to-wall connections.

The structural element selected for analysis of vulnerability to local failure is a one-story section of Pier B. Pier B is also located wholly within one apartment and thus is subject to the full initial effect of an explosion within a single living unit. Pier $B$ is $3-f t(0.91 \mathrm{~m})$ wide and nominally 8-in $(20.3 \mathrm{~cm})$ thick solid brick construction. Loss of one story of Pier B would result in loss of support for a $15-\mathrm{ft}(4.57 \mathrm{~m})$ length of floor (3 ft $(0.91 \mathrm{~m})$ of pier, one $4-\mathrm{ft}(1.22 \mathrm{~m})$ spandrel, and one $8-\mathrm{ft}(2.44 \mathrm{~m})$ spandrel). There is no apparent potential for post-failure arching over such a damaged section.

The axial thrust $F_{N}$ and moment $M_{N}$ in the eighth, fifth, and first story elements (figure 12) which arise from normal gravity load and live loads [40] are summarized in table 2. The dead load is the weight of the elements themselves, as well as the roof and floor slabs tributary to the elements. The live load of interest is the one actually acting at the time the abnormal load occurs. Although limited data are available to determine this [30] it wo, ld be expected to be somewhat less than the survey live loads found in offices [37], which have been observed to be $11-13 \mathrm{psf}\left(527-622 \mathrm{kN} / \mathrm{m}^{2}\right)$. The range of 5 10 psf (239-479 $\left.\mathrm{kN} / \mathrm{m}^{2}\right)$ was therefore assumed in this arialysis; the risk estimates were found to be insensitive to the actual live load because the live load-dead load ratio in masonry structures is very low. Wind loads have been neglected, assuming the probability of a joint occurrence of extreme wind and gas explosion to be negligible. In a statistical sense, the loads thus selected for the analysis would be the mean loads acting on the structure at an arbitrary time instant.

The gas explosion pressure $q_{A B}$ is assumed to be applied uniformly to the interior face of the element, inducing axial force $c_{p} q_{A B}$ and bending moment $c_{m}{ }^{q_{A B}}$ in the column, where $c_{p}$ and $c_{m}$ are influence coefficients. 


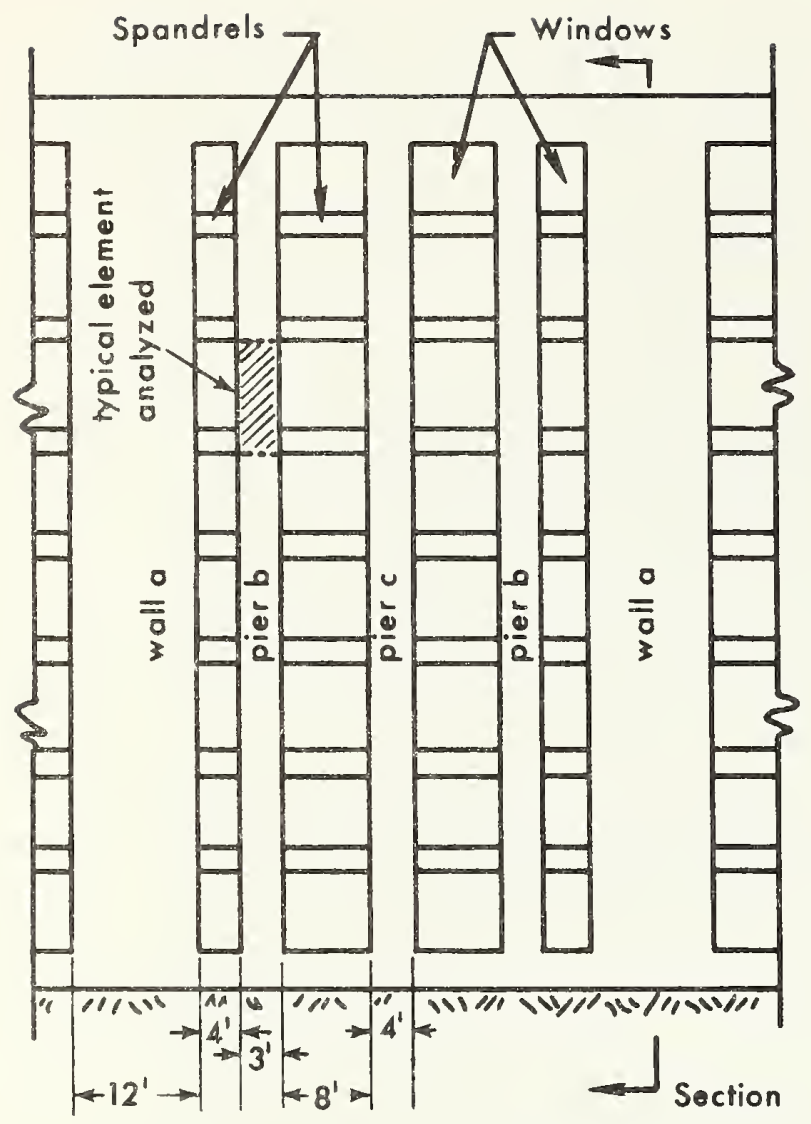

Partial elevation "E"

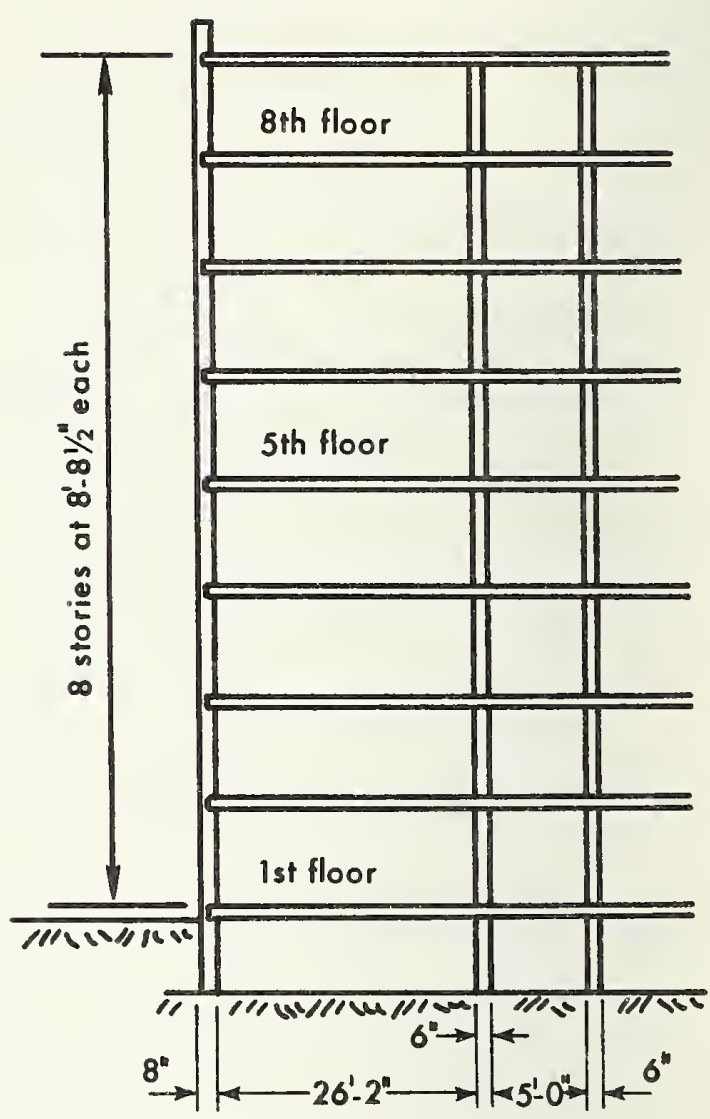

Partial section

Figure 11 Partial Elevation and Section.

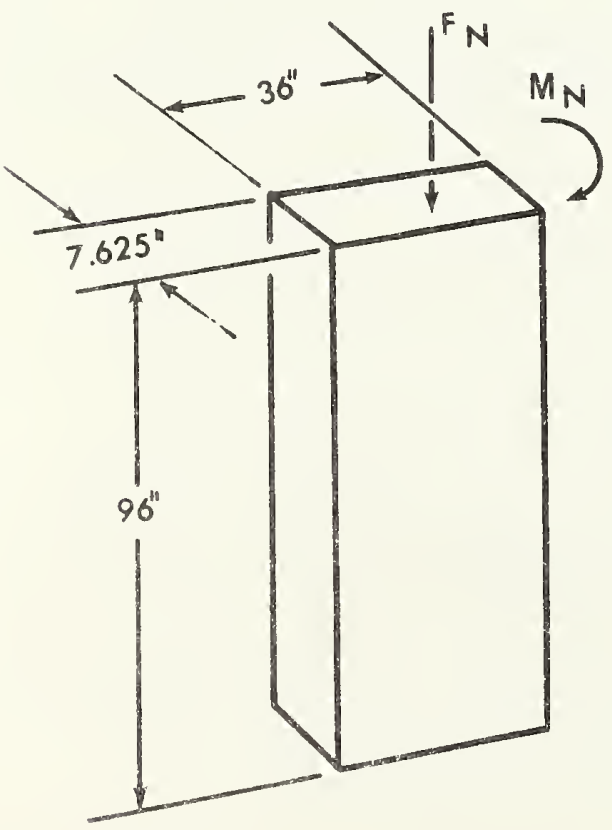

Figure 12 Load-Bearing Brick Masonry Element. 
Table 2. Forces in Masonry Elements under Normal Loads

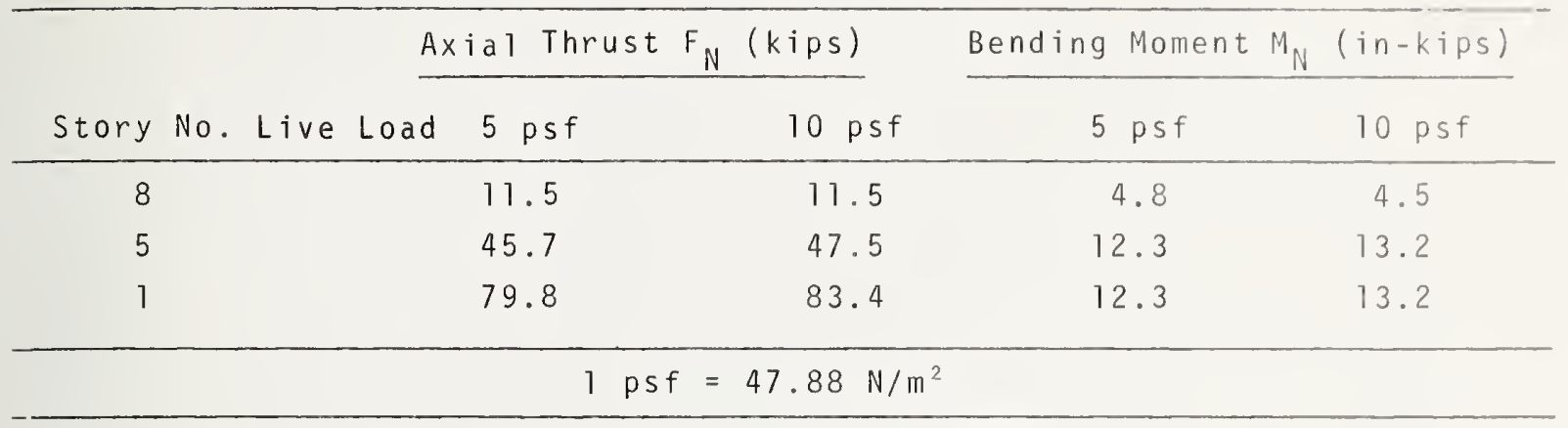

The strength of the masonry wall element in combined bending and thrust is given by Yoke1, Dikkers and Mathey [61] in the form of the interaction diagram shown in figure 13. Three expressions are required to describe the capacity, depending on whether the section cracks prior to failure. Conceptually, the margin of safety $\underset{\sim}{\mathcal{M}}$ is defined along the direction of the resultant applied load $S_{N}$ for normal loads and $\left(S_{N}+S_{A B}\right)$ when an abnormal load acts, as shown in figure 13. The mode of failure may be affected by the occurrence of the abnormal load, since its effect is to reduce the axial thrust while increasing the moment. The applied thrust and moment components of $\left(S_{N}+S_{A B}\right)$ under the combination of normal and abnormal loads are

$$
\begin{aligned}
& P=F_{N}+c_{P} a_{A B} \\
& M=M_{N}+c_{m}{ }^{q_{A B}}
\end{aligned}
$$

The resistance of the element may be defined as the explosion pressure, $q_{R}$, at incipient failure. This definition is simply to make $q_{R}$ and $q_{A B}$ dimensionally consistent, which is required in the subsequent reliability analysis.

Let $e_{c r}=M_{c r} / P_{c r}$, the eccentricity ratio where failure and cracking occur simultaneously. If $M / P>e_{c r}$, cracking occurs prior to failure, and $q_{R}$ may be obtained by substituting $P$ and $M$ from equation 4 into the interaction equations [61], yielding

$$
a_{R}=\max \left(q_{1}, q_{2}\right)
$$

where

$$
\begin{aligned}
& q_{1}=\frac{t / 6\left(s P_{0}+F_{N}\right)-M_{N}+\varepsilon}{c_{m}-c_{p} t / 6} \\
& q_{2}=\left(-B+\sqrt{B^{2}-4 A C}\right) / 2 A
\end{aligned}
$$




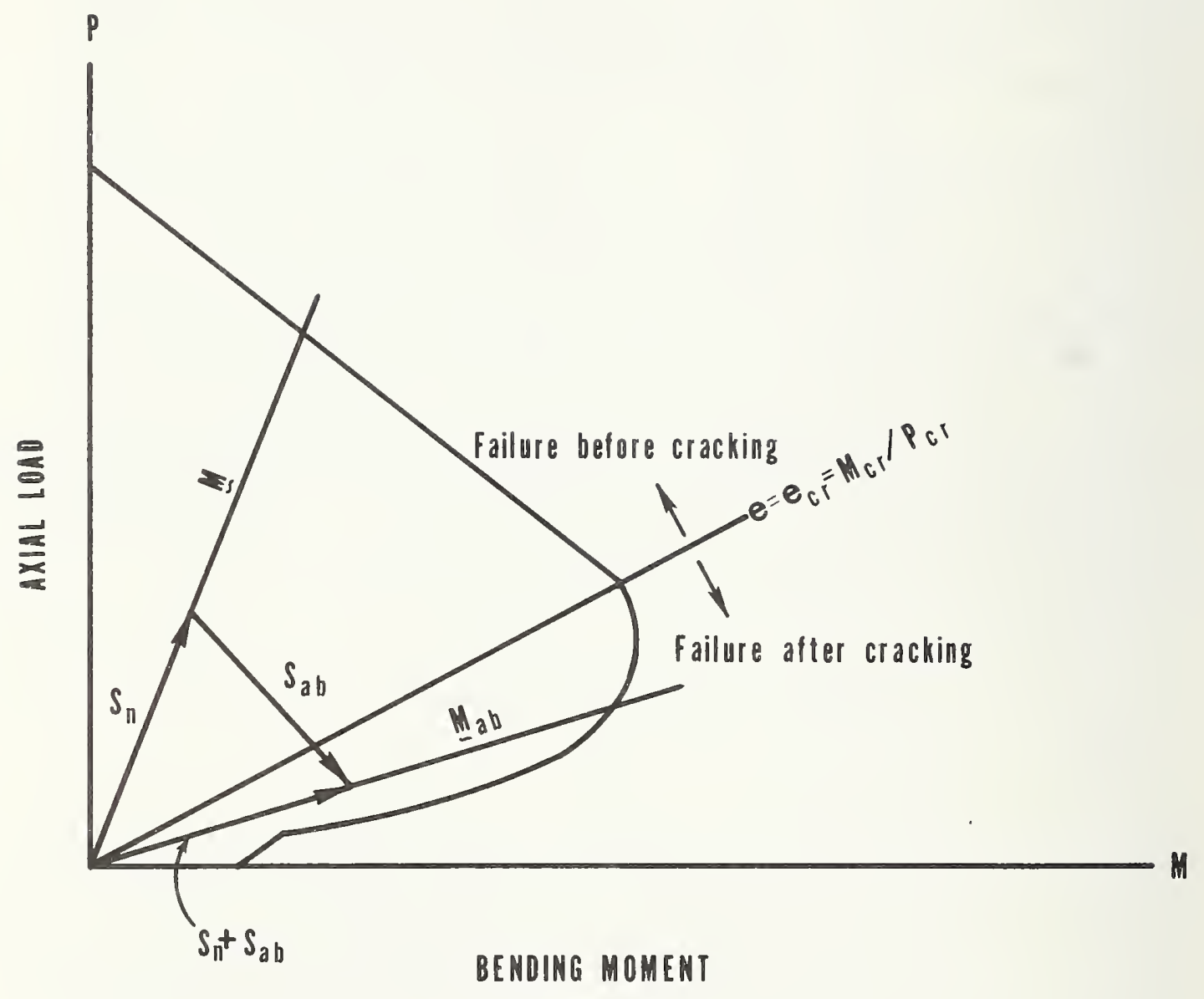

Figure 13 Interaction Diagram for Brick Masonry Section. 
in which

$$
\begin{aligned}
& A=A_{0} c_{p}^{2} \\
& B=2 c_{p} A_{0} F_{N}+c_{m}-c_{p} t / 2 \\
& C=M_{N}-F_{N} t / 2+A_{0} F_{N}^{2}-\varepsilon \\
& A_{0}=\frac{2 t}{3 P} \frac{a-2 s}{(a-s)^{2}}
\end{aligned}
$$

In equations 5, the following notation is employed:

$A_{0}=$ Area of net section

$a=$ Flexural compressive strength coefficient

$f_{m}^{\prime}=$ Compressive strength of masonry

$f_{t}^{\prime}=$ Tensile strength of masonry

$P_{0}=$ Short wall axial load capacity $\left(f_{m}^{\prime} A\right)$

s = Ratio of tensile strength to axial compressive strength of masonry $\left(f_{t}^{\prime} / f_{m}^{\prime}\right)$

$\mathrm{t}=$ Thickness of wall

If $e<e_{c r}$, failure occurs prior to cracking, and

$$
q_{R}=\frac{\left(a P_{0}-F_{N}\right) t / 6-M_{N}+}{c_{m}+c_{p} t / 6} \varepsilon
$$

The term $\varepsilon$ in equations $5 b, 5 c$, and $5 d$ is a random variable with zero mean which denotes the variability in moment capacity exhibited by the experimental data about the interaction strength equation when all the parameters in equations 5 are precisely known. This may be obtained by comparing controlled 
laboratory test data [61] to analysis, wherein the standard deviation $\sigma_{\varepsilon}$ appears to be about 5 in-kips $(0.565 \mathrm{kN}-\mathrm{m})$ for the size of bearing wall element considered here. In addition, $f_{m}, f_{t}, F_{N}, M_{N}$ and $q_{A B}$ are also random variables which contribute additional statistical variability to the resistance and thus affect the design risk.

Conceptualiy, the probability of failure of the bearing wall element under normal and abnormal load may be computed as

$$
p_{f}=P\left(q_{R}<q_{A B}\right)=\int_{0}^{\infty}{ }^{F_{q_{R}}}(x) f_{q_{A B}}(x) d x
$$

where $q_{R}$ and $q_{A B}$ are resistance and load effects, and $F_{q_{R}}(x)$ and $f_{q A B}(x)$ are probability distribution and density functions, respectively, of $q_{R}$ and $\mathrm{q}_{A B}$. Since the member capacity is described by an interactive relationship and the direction of the load vector as well as its magnitude is a random variable (see figure 13), the identification of the appropriate probability distributions and the computation of the failure probability is a formidable task. To perform this computation, the Monte-Carlo simulation procedure summarized in figure 14 is employed. With this approach values of $f_{m}$, $f_{t}$, $F_{N}$, $M_{N}$, and $\varepsilon$ are selected using a random number generator, and the resistance $q_{R}$ is calculated according to equation 5. An abnormal load $q_{A B}$ is then randomily selected and if $q_{R}<q_{A B}$ a failure is recorded. The process is repeated a sufficient number of times that the probability of failure can be estimated as the number of failures divided by number of trials.

For illustrative purposes, it has been assumed that the log normal probability law governs $f_{m}, f_{t}, F_{N}, M_{N}$ and $q_{A B}$, while $\varepsilon$ is normally distributed. The means and statistical uncertainties (coefficients of variation) used in the simulation are summarized in table 3 .

Table 3. Statistics used in Simulation

\begin{tabular}{ccc}
\hline Parameter & Mean & Uncertainty \\
\hline$f_{m}$ & 2900 psi & 0.15 \\
$f_{t}$ & 175 psi & 0.20 \\
$F_{N}$ & $($ Table 2) & 0.12 \\
$M_{N}$ & $($ Table 2) & 0.12 \\
$q_{A B}$ & Varies & 0.36 \\
\hline
\end{tabular}

$1 \mathrm{psi}=6.895 \mathrm{kN} / \mathrm{m}^{2}$ 


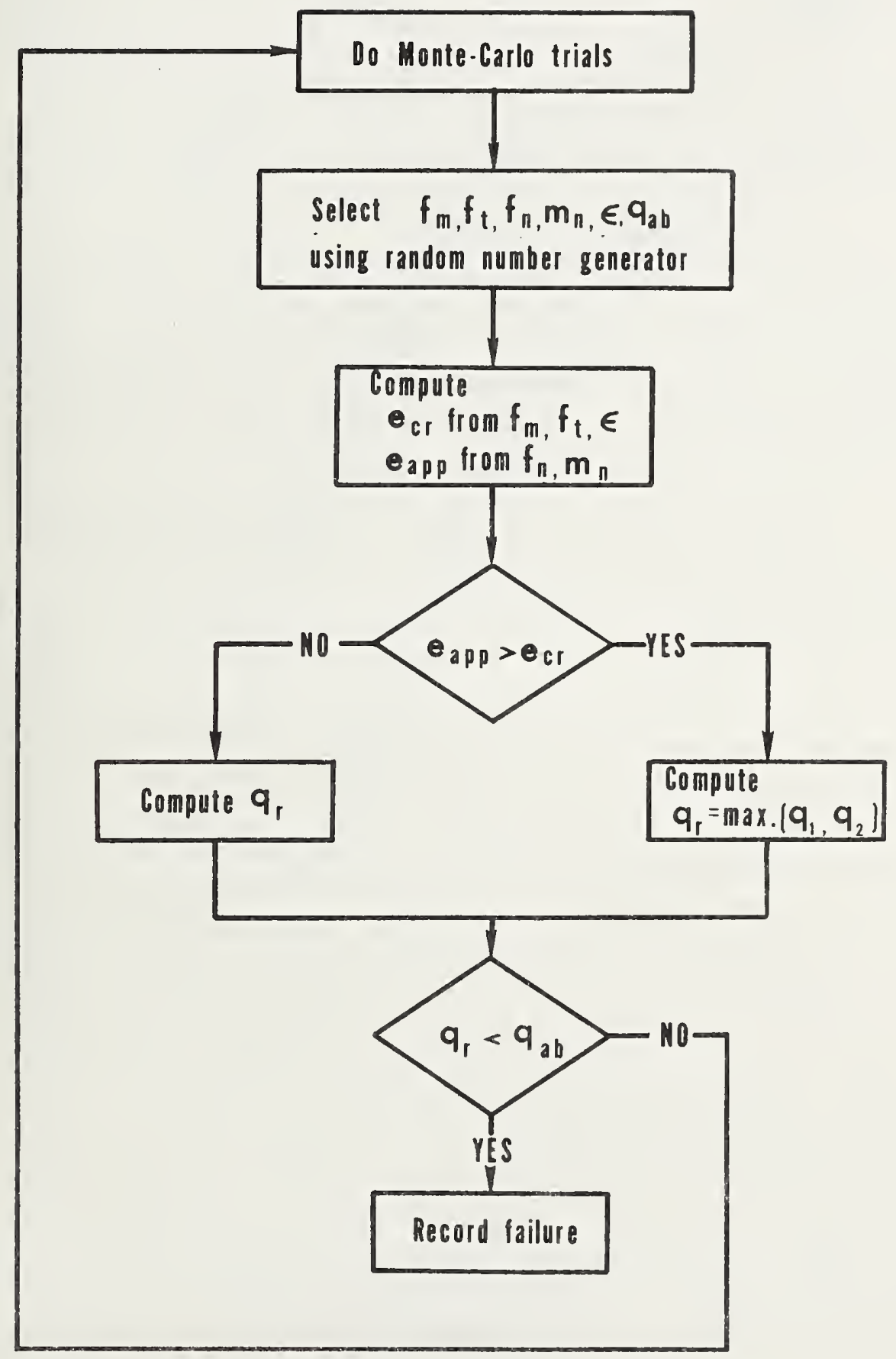

Figure 14 Summary of Monte-Carlo Simulation. 
The material uncertainties are typical for average workmanship and quality control of masonry. The load variabilities reflect the uncertainty in the sum of dead and live loads. Since in typical residential masonry construction the live load-dead load ratio is quite small, this uncertainty is considerably less than that obtained from live load survey data [13,37]. The gas explosion pressure uncertainty was obtained from data reported by Dragosavic [16]; these data are analyzed and discussed in some detail in the Appendix. It might be noted that the risk analysis and conclusions were found to be insensitive to small variations in the statistics in table 3 .

The simulated probability of failure of the bearing wall element is shown in figure 15 as a function of the mean gas explosions pressure $\bar{q}_{A B}$, the story, and the mean live load. One thousand trials were made for each point. The live load magnitude appears to have little effect; this is because the live load-dead load ratio is very small in masonry structures. Abnormal load pressures of 2 to 3 psi ( 14 to $21 \mathrm{kN} / \mathrm{m}^{2}$ ) would not be at all unusual $[16,40,48,56,60]$. The net structural effect of the explosion is to reduce the axial thrust and increase the applied moment on the masonry element. The loss of the beneficial moderate compression (see figure 13) in the element in concert with a sudden increase in flexure is likely to precipitate failure, particularly in the upper story elements where the normal load thrust is sma11. This is reflected in figure 15 where if $\bar{q}_{A B}=2$ psi $\left(14 \mathrm{kN} / \mathrm{m}^{2}\right)$ the failure probability for the eighth story element is 0.83 while for the first story element it is 0.003 .

To place these numbers in some perspective, risks associated with currently acceptable reinforced concrete designs subjected to normal $10 a d s$ have been found to be of the order $10^{-5}$ for flexure and shear [17] and less for compression. When a gas explosion occurs, failure probabilities of the order of 0.01 would be required in order to achieve a similar reliability over the life of the structure (this is discussed further in section 4). The risk associated with the eighth story element therefore is clearly unacceptable from a structural reliability standpoint. Moreover, an eighth story failure could easily propagate down through the rest of the unreinforced masonry structure, resulting in a progressive collapse [40]. specific design provisions to lessen this risk would thus appear to be warranted.

It is apparent from figure 13 that the failure mode, i.e. cracked or uncracked section, will depend on the magnitude of the abnormal load vector $S_{A B}$ which is related to the magnitude of $q_{A B}$. The failure probability may be expressed as

$$
P(F)=P(F \mid C r) \cdot P(C r)+P(F \mid N C r) \cdot P(N C r)
$$




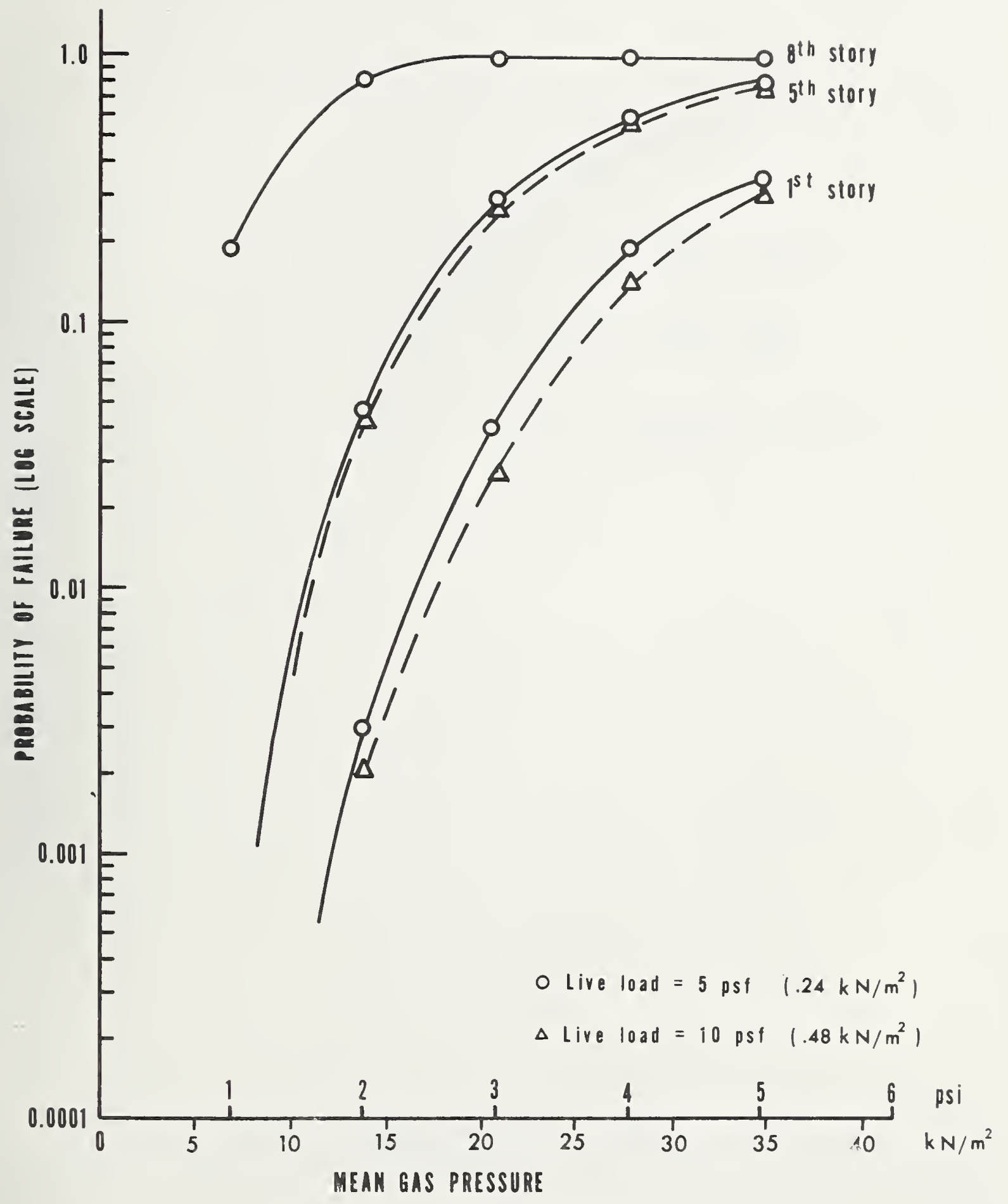

Figure 15 Probability of Failure of Unreinforced Brick Masonry Bearing Wall Under Abnormal Load. 
where $P(F \mid C r)$ and $P(F \mid N C r)$ are probabilities of failure on the condition that the section is cracked and uncracked, respectively, and $P(C r)$ and $P(N C r)$ are, respectively, the probabilities that the appropriate failure mode is the cracked or uncracked section. $P(F \mid C r)$ and $P(F \mid N C r)$ would depend on the relative colinear magnitudes of $S$ and $\underset{\sim}{M}$ (figure 13 ) in the appropriate direction, while $P(C r)$ would be equivalent to $P\left(e_{a p p}>e_{c r}\right)$.

In figure 16, $P(F \mid C r)$ and $P(C r)$ are shown for the fifth story element along with the $P(F)$ from figure 15. As expected, a large $\bar{q}_{A B}$ increases the likelihood of a post-cracking type failure, since a large $\bar{q}_{A B}$ induces a large moment while reducing the axial thrust. It is interesting that $P(F \mid C r)$ appears to furnish a conservative upper bound to the total probability of failure under abnormal load. The relative margin of safety is so great for sections failing prior to cracking, i.e. e app < $e_{c r}$, that $P(F \mid N C r) \approx 0$; this is not especially surprising, since masonry elements have great compressive but relatively little tensile strength. Therefore, in developing criteria for designing masonry structural elements against gas explosions (or other abnormal Toads) it would be a conservative but simplifying assumption to assume that member section cracking occurs prior to failure.

confidence intervals on the statistical estimates obtained from a numerical experiment are helpful in establishing the usefulness of such estimates. The confidence limits depend on the number of Monte-Carlo trials. If the true probability of failure is 0.01 , then the 95 percent confidence limits on the Monte-Carlo estimate are approximately 0.005 and 0.02 if 1000 trials are made [26]. Monte-Carlo simulation may also be used to determine the mean and uncertainty in $q_{R}$ in equation 6 . This requires fewer trials than the calculation of small probabilities. With $\bar{q}_{R}$ and $\delta_{I_{R}}$ available, $P(F \mid C r)$ may be estimated by prescribing lognormal distributions for $q_{R}$ and $q_{A B}[3]$, whence

$$
p(F \mid C r) \approx 1-\Phi\left[\frac{l_{n}\left(\bar{q}_{R} / \bar{q}_{A B}\right)}{\sqrt{\delta_{q_{R}{ }^{2}+{ }^{\delta}{ }^{2}}{ }^{2}}}\right]
$$

where $\Phi($.$) is the standard normal probabitity distribution. Herein, it was$ found that for the fifth story $\delta_{q_{R}}=0.15$, while $\bar{a}_{R} \approx 3.4 \mathrm{psi}\left(23 \mathrm{kN} / \mathrm{m}^{2}\right)$. Using these values, equation 8 is also plotted in figure 16, where it is shown to provide a conservative approximation to the probability estimate obtained by the MontemCarlo procedure. Equation 8 can also be employed to extrapolate the risk analysis into the low probability region, where the required number of Monte-Carlo trials might become prohibitiveiy large. 


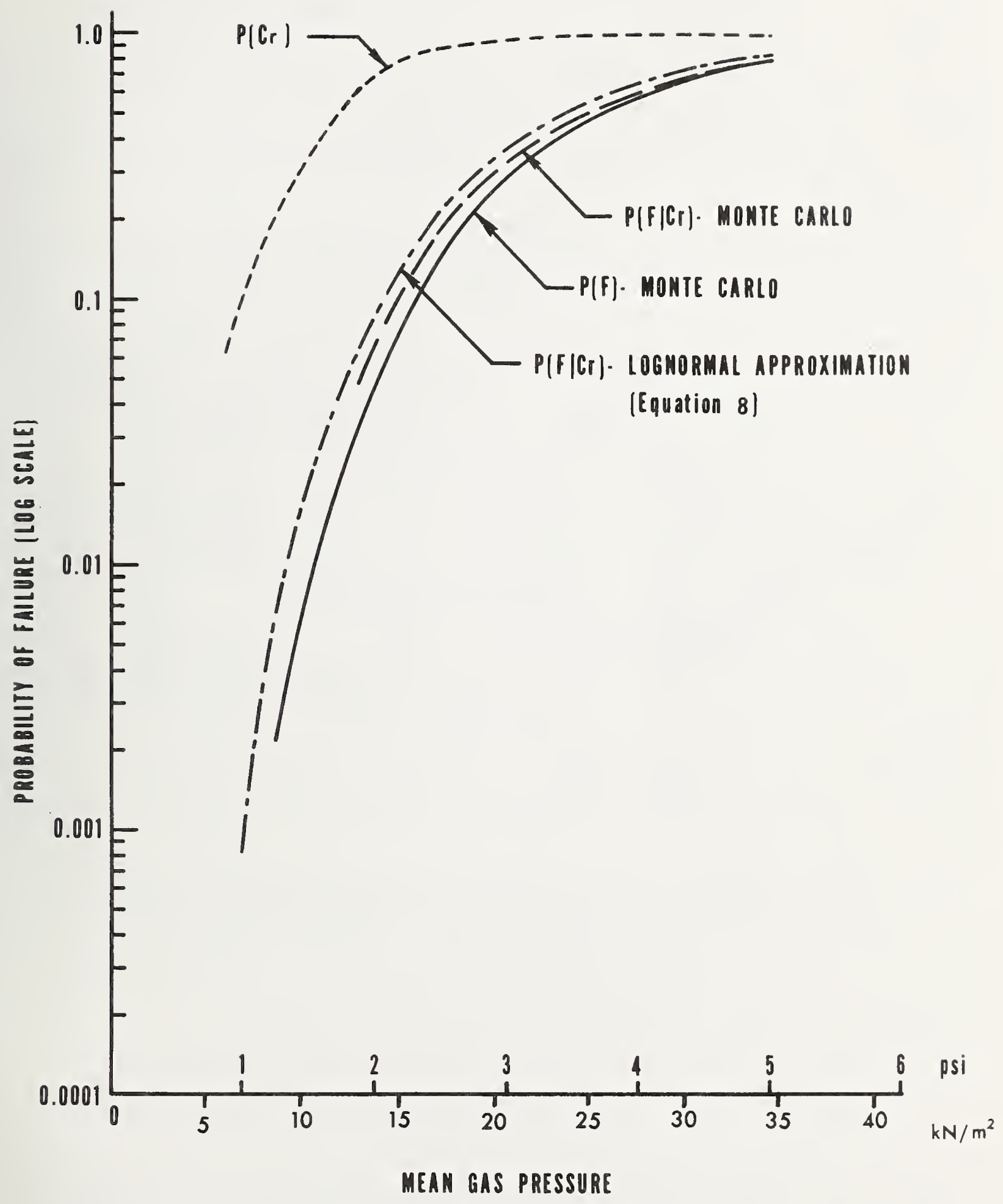

Figure 16 Modal Dependence of Failure Probability - 5th Story. 
Since there is a good chance of local failure, given the abnormal load, the question of whether the failure will progress or be contained must also be answered. If a one-story section of Pier B collapses, the two adjacent spandrels deriving support from that section will fall with it (see figures 11 and 17). The presence of windows on each side of the pier in each story precludes the possibility of effective arching in the plane of the exterior face. An explosion which removes a story-height section of Pier B will also render the drywall partitions of at least the focal apartment incapable of resisting any direct vertical load.

Exactly what would happen during and following the progressive loss of a full Pier B is difficult to analyze quantitatively. It seems clear that the ends of the planks which derive their support from Pier B would deflect a foot or more and that a number of them would pull away from the sagging reinforcing bars that tie the planks together. The restraint at the inner corridor wal1 ends would not prevent this. An optimistic appraisal of the possibilitie is that floor failure would progress upward several stories from the focal point until the cumulative effect of the interior partitions, acting in the fashion of a crumpled egg crate structure, would be sufficient to shore up the remaining floors. A more pessimistic appraisal is that the partitions in the story immediately above the initial failure story would be incapable of resisting collapse of their ceiling planks and that these dry wall partitions would be completely ineffective under the combination of load from above and loss of support from below (the failed ceiling of the apartment with the initial failure). The complete story-by-story failure of this tier of apartments would then progress to the roof. In addition, the falling debris could cause failure to the ground. Inward and lateral spread is a further possibility because of overloading (in both axial force and bending) of the corridor wall and the exterior piers and walls adjacent to the collapsed Pier B.

Regardless of whether one is optimistic or pessimistic in speculating on the consequences of blowing out a one-story section of Pier $B$, one conclusion is clear: failure would be extensive and fall well within any definition of progressive collapse.

To summarize the significant results of this section:

(i) If a gas expiosion pressure of 2 psi $\left(14 \mathrm{kN} / \mathrm{m}^{2}\right)$ nccurs, the probability of brick masonry element failure ranges from 0.003 in the lower story to 0.83 in the top story.

(2) It is conservative to assume that section cracking occurs prior to failure. 


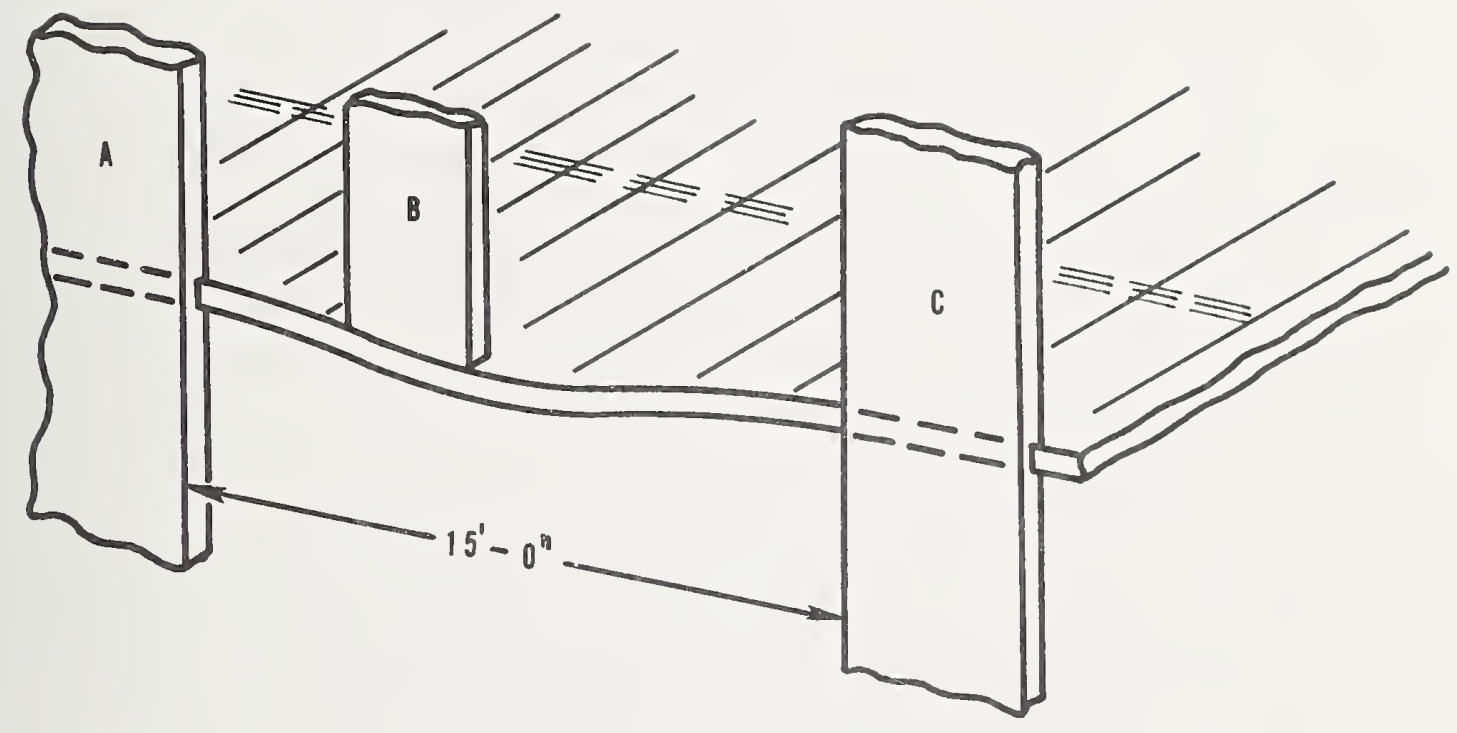

Figure 17 Bridging Mechanism After Brick Masonry Pier Failure. 
In view of the first conclusion, it is disturbing to find that in some proposed design procedures $[28,33,58]$, no special precautions are taken for abnormal loadings in the top stories although they are in the lower stories. The present analysis reveals that the top story elements are most likely to fail in the event of a gas explosion. Therefore, special attention should be paid to insure that either these elements do not fail or that if they do, the failure will be localized. It would be more difficult to support the debris load resulting from their failure than to design to localize the failure.

In this particular design the alternate load paths could not be achieved. Frequently the provision of appropriate floor plan will greatly simplify the development of alternate paths. Other masonry buildings analyzed by McGuire and Leyendecker [40] showed this to be the case.

\section{DIRECT DESIGN STRATEGIES}

\subsection{Introduction}

Direct design strategies to minimize the effects of progressive collapse have been discussed in section 2.3 and consist of (1) the Specific Local Resistance Method and/or (2) the Alternate Path Method. These two approaches are discussed in the following sections.

\subsection{Specific Local Resistance Method}

The method of specific local resistance or reserve load capacity to withstand abnormal events may be implemented in a number of ways. Perhaps the easiest is simply to increase the load factors applied to the normal loads and allow the additional conservatism to protect against abnormal loads. However, as shown in figure 13 the abnormal load may cause the failure mode to change (due to a stress reversal) so that the benefits of increasing safety factors in one limit state only to have the structural element fail in another are marginal. It therefore is apparent that this approach requires a specific abnormal load be identified, so that reserve capacity can be referenced to a specific limit state. Subsequent to the development of specific design criteria, some of the shortcomings of this approach will be identified. It should be emphasized at the outset that these criteria are directed toward those structural elements whose loss would endanger the performance of the remaining structure.

Design criteria which incorporate the effects of uncertainties arising from statistical variability and imperfect information in the parameters should have a probabilistic basis. When the (generalized) structural resistance $R$ and (generalized) applied load effect $S$ are random variables, the relevant indicator of structural safety is the probability of failure, 
as given in equation 6. Symbolically, $p_{f}$ may be expressed as,

$$
p_{f}=p_{f}\left(\gamma, \delta_{R^{\prime}} \delta_{S}\right)
$$

where $\gamma$ is a set of load and resistance factors while $\delta_{R}$ and $\delta_{S}$ are statistical uncertainties in resistance and load effects. When available information is only sufficient to define the means and uncertainties in $R$ and $S$, the reliability of a design may be defined alternatively by the safety index $\beta_{f}$

$$
\beta_{f}=\beta_{f}\left(\gamma, \delta_{R^{\prime}} \delta_{S}\right)
$$

$B_{f}$ may be thought of as the distance (measured in standard deviation units) from a point in design space $(R, S)$, represented by a particular design $\gamma$, to the failure surface defined by the specific limit state. Thus, larger values of $\beta_{f}$ imply higher reliability. It is important to realize that if the probability distributions for. R and $S$ are known, then $\beta_{f}$ and $p_{f}$ are uniquely related; for example, if $R$ and $S$ are mutually independent normal random variables, and the limit state is a linear function of them, $\beta_{f}=$ $\Phi^{-1}\left(1-p_{f}\right)$, where $\Phi^{-1}(\cdot)$ is the percent point function of the standard normal probability distribution function tabulated in statistical texts. Even when probability distributions for $R$ and $S$ are unknown, however, $\beta_{f}$ may be related to general risk levels in an approximate sense; if $\beta_{f}=2.3$, $p_{f} \approx 10^{-2}$, while if $\beta_{f}=3, p_{f} \approx 10^{-3}$. This is important in cases, such as the design for abnormal loads, where no prior information may exist to evaluate an appropriate $\beta_{f}$ through calibration. In any event, when either $p_{f}$ or $\beta_{f}$ is prescribed, a corresponding $\gamma$ may be extracted from equations $9 a$ or $9 b$.

These safety factors should account for the fact that the abnormal load is not only random in magnitude, but in occurrence. It will subsequently be shown that this permits a reduction in the magnitude of the load factors applied to the normal loads when abnormal loads are included in the design equation. Let

$$
\begin{aligned}
F & =\text { structural failure event } \\
N & =\text { normal load event } \\
A B & =\text { abnormal load event. }
\end{aligned}
$$

Using the theorem of total probability, and recognizing that $P(N) \approx 1.0$,

$$
P(F) \approx P(F \mid N)+P(F \mid A B) \cdot P(A B)
$$

If $S_{L T}$ is the normal long-term load effect, the first term is simply $P(F \mid N)=$ $P\left(R<S_{L T}\right)$, which is typicaily $10^{-5}$ or less, as discussed earlier. The second term $P(F \mid A B)=P\left(R<S_{I}\right)$ is analogous to the risk found from the Monte-Carlo simulation, $S_{I}$ being the instantaneous normal plus abnormal load. $P(A B)$ is the probability of occurrence of the abnormal load, which has been discussed in section 2.2 . 
It is important that these two terms be identified separately. $P(A B)$ will remain independent of any structural strategy taken to increase safety, and may be changed only by limiting or controlling the usage of gas. Existing data (section 2) suggest that $P(A B) \approx 18 \times 10^{-6} /$ residential unit/year for gas explosions. On the other hand, $P(F \mid A B)$ may be reduced to acceptable limits independently of $P(A B)$ by increasing the load factors. Equation 10 emphasizes that building safety can be controlled by limiting the risk of abnormal loads (small $P(A B)$ ), by increasing the capacity of key elements or zones (small $P(F \mid A B)$ ), or by a combination of both approaches.

Structural failures resulting from abnormal loads can be controlled in a reasonable way by requiring that the probability of failure of a structural element due to an abnormal load should be less over the life, T, of the structure than its probability of failure under maximum normal loads. Since the lifetime probability of failure from abnormal load has been found in section 2.2 to be $P_{f} P(A B) T$ the above-mentioned design criterion becomes

$$
p_{f}=P\left(R<S_{I}\right)<\frac{1}{T P(A B)} P(F \mid N)
$$

With $P(F \mid N)$ typically about $10^{-5}, T \approx 60 \mathrm{yr}$, and $P(A B)=18 \times 10^{-6}$, an appropriate $p_{f}$ for abnormal load design would appear to be less than 0.01 . An appropriate set $\gamma$ can thus be obtained from equation 9 a using $p_{f}=0.0 ?$, or from equation $9 \mathrm{~b}$ using $\beta_{f}=2.3$. It might be recalled that Monte-Carlo simulation revealed that when normally designed non-reinforced brick masonry bearing walls are subjected to moderate gas explosion pressures, this conditional failure probability may exceed 50 percent.

The design equation takes the form

$$
\bar{\phi} \bar{R}=\bar{\gamma}_{D} \bar{D}+\bar{\gamma}_{L} \bar{L}_{S T}+\bar{\gamma}_{A B} \bar{S}_{A B}
$$

in which $\bar{R}, \bar{L}_{S T}$, and $\bar{S}_{A B}$ are the mean resistance, instantaneous live load, and abnormal load, respectively. Wind load effects have been ignored, reflecting the negligible probability of a joint occurrence of strong wind and abnormal load. Equation 12 may also be written in terms of nominal resistance $R^{\prime}$ and 1 ive load $L_{\text {ANSI }}$ which designers are more familiar with (e.g. American Nationà Standard, ANSI A58.1-1972 [2]), viz.

$$
\phi R^{\prime}=\bar{\gamma}_{0} \bar{D}+\gamma_{L_{-}} L_{A N S}+\gamma_{A B} S_{A B}^{\prime}
$$

in which $\phi=\bar{\phi} \bar{R} / R^{\prime}, \gamma_{L}=\bar{\gamma}_{L} \bar{L}_{S T} / L_{A N S I}$ and $\gamma_{A B}=\bar{\gamma}_{A B} \bar{S}_{A B} / S_{A B}^{\prime}$. 
The live load ratio is determined by comparing mean load survey values [37] with those specified in ANSI A58.1 [2]. It is assumed that the load ratio $\bar{L}_{S T} / L_{A N S I}$ is the same for residences and offices; thus, using Mitchell's data [37], $\bar{L}_{S T^{\prime}} L_{\text {ANSI }}=26$ percent for areas of about 150-200 $\mathrm{ft}^{2}$ (13.94$18.58 \mathrm{~m}^{2}$ ). Eastern European data reported by Karmen [30] tend to support this.

Empirical equations for the abnormal load $S_{A B}^{\prime}$ have been developed from an experimental program [16] which is discussed in the Appendix of this report. As an upper bound equation, Dragosavic recommended that (in $\mathrm{kN} / \mathrm{m}^{2}$ units)

$$
S_{A B}^{\prime}=\max \left[\left(3+\frac{1}{2} p_{v}+\frac{0.04}{\psi^{2}}\right),\left(3+p_{v}\right)\right]
$$

which is an equivalent static gas pressure dependent on venting pressure $p_{v}$ and vent area ratio $\psi=$ (vent area)/(Room volume). A statistical analysis (Annondix) of these data revealed that, based on a 25 percent probability uations $14 \mathrm{D}$ on page 39 and Equations 19 on page 49 should read:

$S_{A B}=\max \left[\left(2+1.2 p_{v}\right),\left(1.2+0.6 p_{v}+\frac{0.05}{\psi^{2}}\right)\right]\left(\mathrm{kN} / \mathrm{m}^{2}\right) \quad(14 \mathrm{a})$,

for $0.05<\psi<0.15$

sLrelcIl \{Jo\} UII LIIE vasis U

gas explosions,

$$
S_{A B}^{\prime}=1.5 p_{V}+2.8 \mathrm{~K}\left(\mathrm{kN} / \mathrm{m}^{2}\right)
$$

for design, where $k$ is the rato of the minimum bounding surface area to the unit area.

A comparison of the pressures obtained from equations $14 \mathrm{a}, 14 \mathrm{~b}$ and $14 \mathrm{c}$ for a typical kitchen $10 \mathrm{ft}(3.05 \mathrm{~m})$ square by $8 \mathrm{ft}(2.44 \mathrm{~m})$ in height with various glazing is shown in table 4. Equation 14 a has been divided by 0.8 to make its comparison with equation $14 b$ consistant (refer to appendix). 


\begin{tabular}{|c|c|c|c|c|c|c|c|}
\hline \multicolumn{3}{|c|}{ Glazing } & \multicolumn{4}{|r|}{$\begin{array}{r}\text { Design } \\
\text { Fsi } \\
\end{array}$} & $\begin{array}{l}\text { Pressures, } \\
\left(\mathrm{kN} / \mathrm{m}^{2}\right)\end{array}$ \\
\hline $\begin{array}{l}\text { No. of } \\
\text { ranes }\end{array}$ & & Size & $\begin{array}{l}\text { Ratio } \\
\text { (Glass Area/ } \\
\text { (Floor Area) }\end{array}$ & $\left\{\begin{array}{l}\text { Equation } \\
14 a \quad[16] \\
\end{array}\right.$ & & $\begin{array}{l}\text { quation } \\
\text { 14b }\end{array}$ & $\begin{array}{l}\text { Equation } \\
14 \mathrm{C}[48,56]\end{array}$ \\
\hline 2 & $2^{\prime} \times 4^{\prime}$ & $\times \quad 3 / 32^{\prime \prime}$ & 0.16 & $2.40(16.6)$ & 2.02 & $2(13.9)$ & $2.5(17.2)$ \\
\hline 1 & $4^{\prime} \times 4^{\prime}$ & $\times 3 / 16^{\prime \prime}$ & 0.16 & $2.61(18.0)$ & 2.23 & $3(15.4)$ & $3.0(20.7)$ \\
\hline 2 & $3-3 / 8^{\prime} \times 6$ & $-3 / 4^{\prime} \times 1 / 4^{\prime \prime}$ & 0.23 & $1.51(10.4)$ & 1.22 & $2(8.40)$ & $1.87(12.9)$ \\
\hline $1 *$ & $2-1 / 2^{\prime} \times 4$ & $1 \times 3 / 321$ & 0.10 & $5.00(34.5)$ & 4.63 & $3(31.9)$ & $3.6(24.8)$ \\
\hline
\end{tabular}

*HUD-MPS requires a minimum of 10 percent of floor area.

It may be observed that in no case does the design pressure exceed the 5 psi $\left(34 \mathrm{kN} / \mathrm{m}^{2}\right)$ required in the Fifth Amendment [55] and CP 110 [12]. However, it should be noted that due to increasing requirements for energy conservation, smaller window areas could lead to increases in design pressures. Where the glazing is a large percentage of floor area, the use of equation 14b also results in additional design economies over either equations 14 a or $14 \mathrm{C}$. Using equation $14 \mathrm{~b}$ for the abnormal load design pressure results in $S_{A B}^{\prime} \geq 1.3 \bar{S}_{A B}$ for those $p_{V}$ and $\psi$ of interest in design.

Finally, the specific load and resistance factors in equation 13 are determined from equation $9 b$, using an iterative procedure for calculating $\bar{\phi}, \bar{\gamma}_{L}$ and $\bar{\gamma}_{A B}$ from $\beta_{f}, \delta_{R}, \delta_{D}, \delta_{L}$ and $\delta_{S_{A B}}$ described by Paloheimo and Hannus [44]. $\delta_{D}$ is quite sma11, say 0.06. Live load survey data for offices [13,37] and residences [30] show that $\delta_{L} \approx 0.60$ for short-term loads. Data for gas explosion pressures generated under nominally identical conditions (same room volume, venting, gas-air mixture) imply that $\delta_{S_{A b}} \approx 0.40$ (See Appendix); the above uncertainties include contributions due to modeling and imperfect information [3,23]. For 99 percent reliability $\left(\xi_{f} \approx 2.3\right)$ and assuming that the mean abnormal load effect conceivably could exceed the mean gravity load effect by a factor of two, equation $9 b$ yields $\bar{\gamma}_{D}=1.01, \bar{\gamma}_{L}=$ 1.37, and $\bar{\gamma}_{A B}=1.65$ in equation 12 for average quality and workmanship. The load factors in equation 13 thus become $\gamma_{L}=1.37 \times 0.26=0.36$ and $\gamma_{A B} \leq 1.65 / 1.3=1.28$; rounding off, the design equation would be,

$$
\phi R^{\prime} \geq D+0.4 L_{A N S I}+1.3 S_{A B}^{\prime}
$$


when the gravity and abnormal load effects superpose. When the gravity and abnormal loads have opposite sense, then

$$
\phi R^{\prime} \geq 1.4 S^{\prime}{ }_{A B}-D
$$

A summary of other load factors and the approximate risks they correspond to is given in table 5 .

Table 5. Load Factor Design for Specific Local Resistance

\begin{tabular}{llll}
\hline$\beta_{f}$ & $\gamma_{L}$ & $\gamma_{A B}$ & $p_{f}$ \\
\hline 1.6 & 0.3 & 1.1 & .05 \\
2.3 & 0.4 & 1.3 & .01 \\
3.0 & 0.4 & 1.4 & .001 \\
\hline
\end{tabular}

Specific $\phi$-factors have not been given because it was considered undesirable to tie the design equation to a specific material. However, for a number of materials, a simple calculation reveals that for the $\beta_{f}$ values of interest here, $\phi \bar{R} \approx R^{\prime}$ and thus in order to simplify, equation 15 could be written without the $\phi-f a c t o r$. Moreover, it was found that for a wide range of $\delta_{R}$ (say $0.10 \leq \delta_{R} \leq 0.25$ ) which cover numerous materials common to construction, the above load factors were quite insensitive to $\delta_{R}$. This implies that the load side of equation 13 is virtually material-independent, and could be included in the "Loads and General Design" section of a model building code.

Equation 15 is similar in form to the abnormal load criteria of the UK [55] Swedish [21] and Dutch [43] building codes, with the exception that it was considered unnecessary to include the wind load term in equation 15 . In all these criteria, the live (and wind) load factors are less than unity. Despite the presence of $\gamma_{A B}$, equation 15 may not be as penalizing as the British or swedish design criteria which require $S_{A B}^{\prime}=5 \mathrm{psi}\left(34 \mathrm{kN} / \mathrm{m}^{2}\right)$ and $5.8 \mathrm{psi}\left(40 \mathrm{kN} / \mathrm{m}^{2}\right)$ respectively; in contrast, equation $14 \mathrm{~b}$ may result in $S_{A B}^{\prime}$ less than 1 psi $\left(6.9 \mathrm{kN} / \mathrm{m}^{2}\right)$, depending on the vent ratio. Moreover, the European criteria do not have a reliability basis, and were derived subjectively.

The necessity of identifying a specific abnormal load (here taken to be a gas explosion) is admittedly a drawback, because of the paucity of abnormal load data with which to develop specifications. It is re-emphasized 
that only elements whose loss would endanger subsequent structural performance need satisfy the abnormal load criteria given above; moreover, these criteria are applicable for all buildings in which specific local resistance must be provided.

It might also be observed that event control may be used to some advantage in reducing the effect of the abnormal load; note, for instance that venting which is a form of event control is included in the gas pressure equation.

\subsection{Alternate Path Method}

In contrast to the specific local resistance approach discussed in the previous section, the concept of providing alternate paths directs attention toward the behavior of the structure after some elements are lost, regardless of cause. This is attractive not only from a philosophical point of view, as the limit state considered is directly relevant to the overall structural performance in the event of an accidental overload, but also because abnormal loads need not be specifically identified in the design equation. It should be emphasized, however, that this by no means obviates the need to understand the characteristics and magnitudes of abnormal load events since such knowledge is generally required in order to predict how much of the structure is actually damaged. For instance the design pressures given by equation $14 b$ provide some basis for estimating the amount of damage that might occur as the result of a gas explosion and hence for applying alternate load path concepts to a specific design situation. However, in situations where gas may not be present, other abnormal load events still are not precluded. Under these circumstances and in the absence of any current reliable data on abnormal load magnitudes it is necessary to specify a priori those damage levels that the structure must tolerate before the alternate path design concepts can be applied.

In the final analysis, the primary objective of designing damage tolerance into structures is to minimize the loss of life that might otherwise occur in the event of an abnormal load, and to permit the safe egress of the occupants from the damaged structure. Naturally, the specification of such tolerable damage limits is largely subjective, and involves technical and social judgment to a significant degree. Because the point is often ignored by engineers and not realized by society in general, it seems worthwhile to note that a balance always exists between safety and economy in design. Obviously, structures could be built which would withstand practically any abnormal load; however, these would be prohibitively costly and, at the same time, would not constitute an optimal utilization of resources from the viewpoint of society at large.

The determination of this optimal point of balance between safety and cost involves a scaling of social values, and an assessment of the willingness on the part of individuals in society to incur risks. One must differentiate 
between risks which are incurred voluntarily (sportcar racing) with those which are incurred involuntarily (occupying a dwelling). Acceptable risks for involuntary activities tend to be two to three orders of magnitude less than for voluntary activities [54] and allowable damage provisions must recognize that exposure to the structural consequences of abnormal loads is involuntary in nature. Finally, it is noted that in developing a standard, widespread use will almost certainly occur before its social and economic impact can be evaluated.

In terms of the safety of occupying structures vis a vis other activities, it may be assumed that these social values have stabilized. Therefore, current tolerable risks associated with other involuntary activities, whether explicitly or implicitly realized, are appropriate as a basis for developing a criterion for acceptable damage following an abnormal load. With these points in mind, it is suggested that the damage be considered tolerable if it is confined to the stories immediately adjacent to the origin of the incident causing damage. Damage resulting from the loss of the primary elements may extend into the story above and below the unit assumed to be the focal point of the abnormal loading event. In any one of the stories, damage should not extend outside an area greater than $750 \mathrm{sq}$. $\mathrm{ft}$ $\left(69.7 \mathrm{~m}^{2}\right)$ or 15 percent of the floor area. It is felt that this requirement will limit fatalities to an average of less than one per incident, which should limit the total average number of annual fatalities to something less than the mortality associated with fires and two orders of magnitude less than that associated with automobile accidents. The damaged zone may be isolated (or contained) within these limits by zoning a structure through the use of expansion joints. This approach appears most appropriate for low-rise structures.

Compliance may be determined by assuming that the primary structural elements are incapable of carrying load, one element at a time, and evaluating the resulting structural behavior. The following definitions of primary structural elements are similar to those used in the U.K. [55] as well as a HUD draft document [57]:

(1) major load carrying beams

(2) floor slabs between supports

(3) columns

(4) bearing wall panels

These recommendations are similar to those used in Denmark [11] as well as those used in the U.K. [55]. Sweden [21] controls the damage by specifying a volume of tolerable damage rather than an area.

When a primary structural element is removed, the remaining structure must continue to carry its existing loads: for a sufficient time at least to 
safely evacuate the structure and inspect the extent of damage. In identifying the appropriate design loads to use in applying the alternate path concept, their duration and frequency relative to those design requirements is of primary interest. It might be recalled, for example, that wind loads were neglected in the specific local resistance approach, because the probability of the joint occurrence of an abnormal load and high wind were deemed negligible. However, since the damaged structure may be expected to function for an extended time, at a reduced level of safety, this assumption may no longer be justified. For these reasons, the effects of short-term wind loads should be included in the design equation used to evaluate the residual strength of a damaged structure. An appropriate load combination thus would be,

$$
\text { Dead + Short-Term Live + Monthly Maximum Wind }
$$

Load factors for use in the design equation are derived using the same procedure as that used to arrive at equation 15. For short-term load effects, $\delta_{L}=0.60$ as before. The uncertainty in the monthly maximum wind load effect is estimated as $\delta_{W}=0.40$, although this may vary from site to site and is based in part on judgment. (It is entirely coincidental that $\delta_{W}$ is the same as $\delta_{S_{A B}}$ ) In order to write the design equation in terms of familiar ANSI A58.1 10ads, note that $\bar{L}_{S T} / L_{A N S I}=26$ percent as before, and $\bar{W} / W_{A N S I}=10-20$ percent if $\bar{W}$ is the mean monthly maximum wind speed. For a reliability of 99 percent for the damaged structure $\left(\beta_{f}=2.3\right)$, with $[/ \bar{D} \leq$ 0.5 and $\bar{W} / \bar{D} \leq 0.25, \bar{\gamma}_{L}=1.90$ and $\bar{\gamma}_{W}=1.20$ in equation 12 from equation $9 \mathrm{~b}$; the design equation for applying the alternate path concepts thus becomes,

$$
\phi R^{\prime} \geq D+0.5 L_{\text {ANSI }}+0.2 W_{\text {ANSI }}
$$

when gravity and wind load effects have the same sense. When they oppose one another,

$$
\phi R^{\prime} \geq D-0.3 W_{A N S I}
$$

the dead load factor being rounded to unity in both cases. Specific $\phi$ factors have not been given so as not to limit equation 17 to one particular material. As before, the load side of equation 17 is insensitive to small variations in $\delta_{R}$, implying its applicability to different construction materials. Numerous factors may be considered when designing a structure to bridge over a damaged zone. These factors include:

(1) Floor plan - The selection of a proper floor plan layout of walls and columns is possibly the most important aspect of 
designing a building which will possess alternate load paths. While it is difficult to give all possible features of a good floor plan, desirable features include longitudinal spine walls (walls perpendicular to cross walls) which serve to enhance both the stability of the cross walls and limit the amount of wall damaged in an abnormal loading event. Other stabilizing features might include stair wells or elevator shafts.

(2) Short returns on walls - A return is a short length of wall usually at right angles to another wall.

(3) Redistribution of floor slab load - A slab which has lost its support along one edge should be able to change span directions and transmit load to other supports.

(4) Internal partitions - The strength of partitions normally neglected in design may be utilized.

(5) Catenary action - Slab span may increase as the result of loss of an intermediate support. Loads may be carried by catenary action with accompanying large deflections.

(6) Beam action of walls - If a bearing wall is damaged, the load may be distributed into the stories above by beam action of walls. That is, the walls may be considered to act as webs of deep beams with floor slabs as flanges. However, walls and slabs must be adequately tied together.

(7) Arching action - In-plane arching of walls may serve to bridge over a damage zone in masonry construction.

Design examples using these principles have been discussed by Taylor [59] and Haseltine and Thomas [27,28]. These authors point out that the concepts are relatively easy to apply if incorporated at the design stage. McGuire and Leyendecker [40] have shown that it is relatively easy to check the resistence of a building to progressive collapse by rather simple analysis.

It should be pointed out that in the event an alternate patn cannot be developed, it may be necessary to design strong points into a structure using the method of specific local resistance. Therefore, the two design concepts discussed in sections 4.2 and 4.3 are not entirely mutually exclusive, and in some instances may be used to complement each other.

Use of the alternate path concept will result in a structure with the coherence to limit the spread of collapse. Use of the method represents a feasible means of determining minimum requirements for strength and continuity which can result in buildings said to possess structurai integrity.

The provision in a code of specified minimums for strength and continuity is attractive for the typical structure if the requirements are sufficient to develop an alternate path. However, unless the reasons for the minimums are 
apparent in the code, a designer of an unusual structure may overlook the need for considering progressive collapse. Such minimum requirements would have to be established for different types of construction and would have to be carefully updated as construction practices change. Nonetheless the concept is useful since, if the provisions are adequate, then design for progressive collapse might require nothing more than a final check after the usual design is completed. It should be noted that the Department of Housing and Urban Development is currently sponsoring research on large panel construction at the Portland Cement Assocation. One aspect of the research concerns establishing levels of minimum strength and continuity required to achieve structural integrity for that particular type of construction.

\subsection{Design Applications in the United States}

In 1969 the Department of Housing and Urban Development (HUD) initiated operation BREAKTHROUGH, a program designed to encourage the development and introduction of industrialization into the housing industry in the United States. The National Bureau of Standards, on behalf of HUD, drafted criteria [8] which were used to guide the development and subsequent evaluation of these housing systems. These "Guide Criteria" contained a recommendation against progressive collapse under catastrophic loading which was similar in concept to the "Fifth Amendment." Cost data for incorporating these progressive collapse provisions in design are not meaningful since, for the most part, the systems requiring provisions were adaptations of existing designs which were subsequently modified to meet the criterion. The solutions used in five of the systems were documented in detail by Yokel, Pielert, and Schwab [62]. They concluded that:

1. The systems with clear spans between transverse bearing walls greater than $19 \mathrm{ft}(5.79 \mathrm{~m})$ had to use "strong" transverse bearing walls at least for the end walls and the transverse walls next to the end walls. In all cases, special provisions had to be made to provide lateral support to the end walls.

2. The systems with clear spans of $12 \mathrm{ft}(3.66 \mathrm{~m})$ or 1 ess relied principally on alternate paths of load support.

3. In short-span systems using an alternate path of load support the following joint reinforcement ties were the most critical: horizontal ties in the vertical joints between adjacent or intersecting bearing walls; continuous vertical ties throughout the building in the same joints; transverse horizontal ties between corridor floor panels and adjoining floor panels; and ties between transverse walls and corridor walls and between transverse walls and corridor floor panels. The alternate mode of load support was also assisted by longitudinal horizontal ties between adjoining floor panels on 
either side of transverse bearing walls, ties between transverse bearing walls and connecting floor panels, and vertical ties between successive transverse bearing wall panels.

Thus, depending on the span length, the systems used either the alternate path approach or a combination of the alternate path with strong points provided by specific local resistance.

\section{CONCLUSIONS AND RECOMMENDATIONS}

\section{1 Summary}

This report has discussed the basic concepts underlying design procedures which reduce the risk of progressive collapse and has summarized the background leading to the concepts. Progressive collapse was defined as a chain reaction or propagation of failures following damage to a relatively small portion of a structure in which the resulting damage is characteristically out of proportion to the damage which initiated the collapse.

Abnormal loading events are those events which, although they may have a low probability of occurrence relative to traditional structural design loads, may precipitate catastrophic structural failure if they occur. The gas explosion, bomb explosion, and vehicular collision appear to be the main sources of abnormal loadings on building structures. A case study of the probability of structural failure due to a gas explosion has been made.

Strategies for reducing the risk of progressive collapse in any type of building have been described as (1) Event Control, (2) Direct Design, and (3) Indirect Design. These strategies were discussed in detail and finally a brief description of design applications in the U.S. was given. This type of collapse may occur either during construction or after completion of the structure, and although certain portions of the report should be useful in deriving design guidelines for buildings under construction, the scope of the report was limited to the development of guidelines for completed buildings.

\subsection{Conclusions and Recommendations}

The following conclusions and recommendations are based upon supporting data contained in this report.

5.2.1 A progressive or chain reaction type of failure may result as - consequence of normal or abnormal load events.

5.2.2 Abnormal load events constitute an unacceptable hazard in buildinas of all types of construction and should be considered in the formulation of building regulations. 
5.2.3 The normal design process results in a certain amount of strength and continuity which is also available to resist progressive collapse. This has been demonstrated in the past on a number of occasions. However, since codes, standards, and building materials, as well as construction techniques change with time, it cannot be assumed that this protection will always be provided in the future. Therefore, it is considered necessary that progressive collapse provisions be included in design requirements.

5.2.4 The three approaches for reducing the risk of a progressive or chain reaction type of failure are (1) Event Control, (2) Direct Design, and (3) Indirect Design. Only the latter two approaches are considered practical since Event Control is dependent on factors that are often outside the control of the designer.

5.2.5 The Direct and Indirect Design approaches should satisfy the following performance statement.

Structures should be designed so that there is reasonable probability, if local damage occurs, that the structure as a whole will not be damaged to an extent disproportionate to the original cause of the rocar damage.

5.2.6 Direct Design refers to explicit consideration of resistance to progressive collapse during the design process. The two basic means are (1) the Alternate Path Method and (2) the Specific Local Resistance Method. The use of the former is preferred since it is concerned with the stability of the building after the loading event has occurred.

5.2.7 The following procedure may be followed when using the Alternate Path Method:

(a) Estimate the amount of damaged structure considerina feasibie Add the following sentence at the end of paragraph $5.2 .7(\mathrm{a})$ (pg. 48) However, the absence of gas does not preclude the use of the minimum damage described in paragraph $5.2 .7($ b) .

(1) major load carrying beams

(2) floor slabs between supports

(3) columns

(4) bearing wall panels. 
(c) Following removal of the primary structural element the structure should be designed for the following ultimate loads:

$$
\begin{aligned}
& \phi R^{\prime} \geq D+0.5 L_{\text {ANS I }}+0.2 W_{\text {ANS I }} \\
& \phi R^{\prime} \geq D-0.3 W_{\text {ANSI }}
\end{aligned}
$$

Under these conditions damage is to be expected but there is time for evacuation and assessment of damage.

5.2.8 Specific $10 \mathrm{cal}$ resistance should be provided when it becomes impractical to employ the alternate path method. It should be noted that designing to resist the loading events may, coincidentally, provide sufficient strength and continuity to achieve alternate paths. The following procedure may be used:

(a) In the absence of more complete data, the gas explosion may be selected as the normative abnormal loading event since it occurs with Equations $14 \mathrm{D}$ on page 39 and Equations 19 on page 49 should read:

$$
\begin{array}{r}
S_{A B}^{\prime}=\max \left[\left(2+1.2 p_{v}\right),\left(1.2+0.6 p_{v}+\frac{0.05}{\psi^{2}}\right)\right]\left(k N / m^{2}\right) \quad(14 a), \\
\text { for } 0.05<\psi<0.15
\end{array}
$$

should be included if a site study warrants them.

(b) For specific local resistance design, the gas pressure may be used in the following equation

$$
R^{\prime} \geq D+0.4 L_{A N S I}+1.3 S^{\prime}{ }_{A B}
$$

(c) In those instances where other abnormal loads can be identified, their consideration in design is required.

5.2.9 The Alternate Path and Specific Local Resistance Methods may be used in conjunction with each other in a design.

5.2.10 Minimum requirements for use in the Indirect Design approach have not been established for specific construction types. Research should be started in this area. 
5.2.11 A design procedure which may eventually result in very little additional structural design effort is shown in figure 10. An engineer would proceed with a normal design which would incorporate specified minimum values of strength and continuity (Indirect Design). Presuming the structure is not judged unusual by a building official, provision of the minima would serve as compliance for providing the required progressive collapse resistance. An unusual building would require resorting to the general performance requirement. The Direct Design approach could then be used to develop the required resistance.

5.2.12 The preceding conclusions apply to all construction types; however, it is recognized that the degree of concern and the difficulty in developing solutions is greater for some types than for others.

\section{ACKNOWLEDGMENTS}

The authors would like to thank Mr. J.R. Harris, Dr. C. Culver and Dr. F. Y. Yokel of the Center for Building Technology, National Bureau of Standards; Mr. W. J. Werner of the Office of Policy Development and Research, Department of Housing and Urban Development; and Dr. J. E. Breen of the Department of Civil Engineering, the University of Texas at Austin for their technical review of the manuscript. 
[1] Allen, D. E. and Schriever, W. R., Progressive Collapse, Abnormal Loads, and Building Codes, Structural Failures: Modes, Causes, Responsibilities - a compilation of papers printed at the ASCE National Meeting on Structural Engineering, Cleveland, Ohio, April 1972, published by ASCE, New York (1973).

[2] American National Standard Building Code Requirements for Minimum Design Loads in Buildings and Other Structures, A58.1-1972. American National Standards Institute, Inc., New York, New York, 10018 (1972).

[3] Ang, A. H.-S. and Corne11, C. A., Reliability Bases of Structural Safety and Design, Journal of the Structural Division, ASCE, Vol. 100, No. ST9 (Sept. 1974).

[4] The Behavior of Structures When They Resist Explosions, Editorial Comment, Concrete, London, Vo1. 4, No. 3 (March 1970), p. 87.

[5] Breen, J. E., editor, Summary Report, Research Workshop on Progressive Collapse of Building Structures, HUD-PDR-182, Department of Housing and Urban Development, Washington, D. C. 20410 (September, 1976)

[6] Building Regulations and Public Health and Safety, Editorial Comment, Concrete, London, Vol. 4, No. 5 (May 1970), p. 165.

[7] Building Regulations: The Fifth Amendment and the Freedom to Design, Editorial Comment, Concrete, London, Vol. 3, No. 9 (Sept. 1969), pp. $343-344$.

[8] The Building Research Division Team, Guide Criteria for the Evaluation of Operation Breakthrough Housing Systems, Accession Numbers PB-212055, 212056, 212058, National Technical Information Service, Springfield, Va. (December 1970).

[9] Burnett, E. F. P., Abnormal Loadings and the Safety of Buildings, Industrialization in Concrete Building Construction, Publication SP 48 , American Concrete Institute, Detroit (1975).

[10] Burnett, E. F. P., The Avoidance of Progressive Collapse: Regulatory Approaches to the Problem, NBS-GCR 75-48, National Bureau of Standards, Washington, 0.C. 20234 (October 1975).

[11] Bygningsregiement for Kobstaederne Oz Landet. Tillaey Nr. 3. Midlertidge Krav Til Byningers Stabilitet. (Building Regulations for Urban and Rural Areas. Amendment No. 3. Provisional Requirements for the Stability of Buildings), The Ministry of Housing, Denmark (February 1969).

[12] Code of Practice for the Structural Use of Concrete, CP110: 1972, The British Standards Institution, London (1972).

[13] Culver, C., Survey Results for Fire Loads and Live Loads in Office Buildings, National Bureau of Standards, Building Science Series 85 , U.S. Government Printing Office, Washington, D. C., 20402. 
[14] Despeyroux, J., L'Effondrement De L'Immeuble De Ronan Point Et Ses Consequences En Matiere De Codification (The Collapse of the Ronan Point Building and its Consequences with Regard to Code Writing), Annales de 1 'Institut Technique du Batiment et des Travaux Publics, No. 263, (November 1969), pp. 1800-1803.

[15] Dragosavic, M., Research on Gas Explosions in Buildings in the Netherlands, Notes Reference No. 354/72, Symposium on Buildings and the Hazards of Explosion, Building Research Station, Garston, England (1972).

[16] Dragosavic, M., Structural Measures Against Natural-Gas Explosions in High-Rise Blocks of Flats, Heron, Vol. 19, No. 4 (1973), 51 pp.

[17] Ellingwood, B. R., Probabilistic Study of Safety Criteria for Design, Structural Research Series No. 387, Dept. of Civil Engineering, University of Illinois at Urbana-Champaign (June 1972).

[18] Flats Constructed with Precast Concrete Panels, Appraisal and Strengthening of Existing High Blocks: Design of New Blocks, Ministry of Housing and Local Government, Circular 62/68, London, England (November 15, 1968).

[19] Fintel, M. and Schultz, D. M., A Philosophy for Structural Integrity of Large Panel Buildings, Journal of the Prestressed Concrete Institute, Vol. 21, No. 3, Chicago (May 1976).

[20] Firnkas, S., Concrete Panel Building System: Progressive Collapse Analyzed, Civil Engineering - American Society of Civil Engineers (November 1969), pp. 60-62.

[21] Fortskridanda Ras (Design to Avoid Progressive Collapse), The National Swedish Board of Urban Planning, Publication No.63 (July 1, 1973).

[22] Fry, J. F., Gas Explosions Attended by Fire Brigades in Dwellings, Journal of the Institute of Fuel, England (August-September 1971).

[23] Galambos, T. V. and Ravindra, M. K., Tentative Load and Resistance Factor Design Criteria for Steel Buildings, Structural Division Research Report No. 18, Washington University, St. Louis (Sept. 1973).

[24] Granström, S. and Carlsson, M., Byggforskningen T3: Byggnaders Beteende Vid Överpoverkningar (The Behavior of Buildings at Excessive Loadings), Swedish Institute of Building Research, Stockholm, Sweden (1974).

[25] Griffiths, H., Pugsley, A. and Saunders, 0., Report of the Inquiry into the Collapse of Flats at Ronan Point, Canning Town, Her Majesty's Stationery Office, London, England (1968).

[26] Hald, A., Statistical Theory with Engineering Applications, John Wiley and Sons, Inc., New York (1952).

[27] Haseltine, B. A. and Thomas, K., Load-Bearing Brickwork-Design for Accidental Forces, Clay Products Technical Bureau, Technical Note 6 , Vo1. 2, London (JuTy 1969). 
[28] Haseltine, B. A. and Thomas, K., Load-Bearing Brickwork Design for the Fifth Amendment (To the 1970 Building Regulations), Technical Note Vol. 1, No. 3., Brick Development Association, England (July 1971).

[29] Hodgkinson, A., What the Post-Ronan Point Building Regs Mean, The Architects' Journal, London (February 25, 1970), p. 473.

[30] Karman, T. von, Untersuchungen uber die Nutzlaster von Decken bei Wohngebauden, (Investigation of Live Loads on Floors in Residential Buildings) Osterreichische Ingenieur, Zeitschrift Jg 9 (1966).

[31] Large Panel Structures, Concrete, London, Vol. 3, No. 7 (July 1969), p. 262.

[32] Large Panel Structures, Editorial Comment, Concrete, London, Vol. 3, No. 6 (June 1969), p. 213.

[33] Large-Panel Structures and Structural Connections in Precast Concrete, Addendum No. 1 (1970) to British Standard Code of Practice CP 116:1965 and CP:Part 2: 1969, British Standards Institution, London, England (1970).

[34] Leyendecker, E. V. and Burnett, E. F. P., The Incidence of Abnormal Loading in Residential Buildings, National Bureau of Standards, Building Science Series 89, U. S. Government Printing Office, Washington, D. C., 20402 (September 1976).

[35] Ligtenberg, F. K., Structural Safety and Fire (1.3) Build International, London, Vol. 4, No. 5 (September/October 1971).

[36] Mainstone, R. J., The Effects of Explosion on Buildings, Notes References No. 352/72, Building Research Station Symposium, Buildings and the Hazard of Explosion, Garston, England (0ctober 18, 1972).

[37] Mitchell, G. R. and Woodgate, R. W., Floor Loadings in Office Buildings - The Results of a Survey, Building Research Current Paper, CP 3/71, Building Research Establishment, Department of the Environment, Garston, Watford, England.

[38] Mr. Hubert Bennett on Ronan Point, News of the Month, Concrete, London, Vol. 3, No. 6 (June 1969), p. 215.

[39] McGuire, W., Prevention of Progressive Collapse, Proceedings of the Regional Conference on Tall Buildings, Asian Institute of Technology, Bankok, Thailand (January 1974).

[40] McGuire, W. and Leyendecker, E. V., Analysis of Non-Reinforced Masonry Building Response to Abnormal Loading and Resistance to Progressive Collapse, NBSIR 74-526, National Bureau of Standards, Washington, D.C. 20234 (November 1974).

[41] National Building Code of Canada, 1970. (NRC 11246), Associate Committee on the National Building Code, National Research Council of Canada, Ottawa, Ontario, Canada (1970).

[42] National Building Code of Canada, 1975, (NRC 13982), Associate Committee on the National Building Code, National Research Council of Canada, ottawa, Ontario, Canada (1975). 
[43] Netherlands Standard NEN 3850: Technische grondslagen voor de berekening van bouwconstructies (Regulations for the Design of Building Structures) - TGB 1972, Nederlands Normalisatie Instituut, Rijsivijk, Netherlands (1972).

[44] Paloheimo, E. and Hannus, M., Structural Design Based on Weighted Fractiles, Journal of the Structural Division. American Society of Civil Engineers, Vol. 100, No. ST7 (Ju1y 1974).

[45] Popoff, A., Jr., Designing Against Progressive Collapse, PCI Design Seminar, Tacoma, Washington (October 1972).

[46] Popoff, A., Jr., Stability of Precast Concrete Systems Buildings, ASCEIABSE International Conference on Ta 11 Buildings, Proceedings, Vol. III, Lehigh University, Bethlehem, Pennsylvania (1972) pp. 571-583.

[47] Proposed Amendments to the Buildings Regulations 1965, Ministry of Housing and Local Government, London, England (May 30, 1969).

[48] Rasbash, D. J., Explosions in Domestic Structures; Part 1: The Re1ief of Gas and Vapour Explosions in Domestic Structures, The Structural Engineer, Vol. 47, No. 10 (October 1969), pp. 404-408.

[49] Recommendations Internationales Unifiees Pour Le Ca]cul Et L'Execution Des Constructions En Panneaux Assembles De Grand Format (International Recommendations for the Design and Construction of Large-Panel Structures), Comite Europeen du Beton, Bulletin No. 60, Paris, April 1967, English translation by $C$. V. Amerogen, Cement and Concrete Association, No. 137, London (July 1968).

[50] Robinson, J. R., Observation Sur Les Conclusions Du Rapport De La Commission D'Enquete De Ronan Point (Observation on the Conclusion of the Report of the Inquiry Commission on Ronan Point), Annales de l'Institut Technique du Batiment et des Travaux Publics No. 263, Paris (November 1969), pp. 1797-1799.

[51] Rules and Regulations Relating to Resistance to Progressive Collapse under Extreme Local Loads, Housing and Development Administration, Department of Buildings, The City Record, New York (August 2, 1973).

[52] Saillard, Y., Le Comportement De L'Immeuble De Ronan Point En Comparaison Des Principles De Base Des Recommandations Internationales 'Structures En Panneaux' du Comite Europeen du Beton (Behavior of the Ronan Point Building Compared to the Basic Principles of the International Recommendation "Panel Structures" of the Comite du Beton). Annales de 1'Institut Technique du Batiment et des Travaux Publics, No. 263, Paris (November 1969), pp. 1804-1806.

[53] Somes, N. F., Abnormal Loadings on Buildings and Progressive Collapse, a paper in Building Practices for Disaster Mitigation, National Bureau of Standards, Building Science Series 46, U.S. Government Printing Office, Washington, D.C. 20402, (February 1973). 
[54] Starr, C., Social Benefit Versus Technological Risk, What is our Society Willing to Pay for Safety?, Science, Washington, D.C., Vol. 165 (Septtember 1969), pp. 1232-1238.

[55] Statutory Instrument 1970 No. 109, The Building (Fifth Amendment) Regulations, Her Majesty's Stationery Office, London, England (1970).

[56] Stretch, K. L., Explosions in Domestic Structures; Part Two: The Relationship Between Containment Characteristics and Gaseous Reactions, The Structural Engineer, London, Vol. 47, No. 10 (October iyby), pp. 408411 .

[57] Structural Design Requirements to Increase Resistance of Buildings to Progressive Collapse, Proposed HUD Handbook by the HUD Staff, U.S. Department of Housing and Urban Development (November 1973).

[58] The Structural Use of Precast Concrete, British Standard Code of Practice CP116: 1965 and Part 2: 1969, The British Standards Institution, London .

[59] Taylor, D. A., Progressive Collapse, Canadian Journal of Civil Engineering, Vol. 2, No. 4 (December 1975).

[60] Taylor, N. and Alexander, S. J., Structural Damage in Buildings Caused by Gaseous Explosions and Other Accidental Loadings, CP 45/74, Building Research Establishment, England (March 1974).

[61] Yoke1, F. Y., Mathey, R. G., and Dikkers, R. D., Strength of Masonry Walls Under Compressive and Transverse Loads, Building Science Series 34 , U. S. Government Printing Office, Washington, D.C. 20402 (March 1971).

[62] Yoke1, F. Y., Pielert, J. H. and Schwab, A. R., The Implementation of a Provision Against Progressive Collapse, NBSIR 75-715, National Bureau of Standards, Washington, D.C. 20234 (August 1975). 


\section{APPENDIX. GAS EXPLOSION PRESSURES}

In the main body of this report, the load induced by a natural gas explosion was identified as the normative abnormal load for purposes of analysis and design. This selection was made because of widespread usage of gas and because the incidence of occurrence appears to be an order of magnitude higher than other abnormal loads. Furthermore it would be quite uneconomical or impractical to ban the use of gas, employ automatic suppression systems on a wide scale in residences, or take nonstructural preventive measures that might be feasible with other abnormal loads [36].

It is necessary to have some feeling for the magnitude of gas explosion pressures regardless of which design concept is used to minimize their effect on a structure. This pressure may be required either to design a specific element to resist it or to identify potential damage when applying the alternate path concepts. In the following, the design pressures obtained from a recent experimental program [16] are examined, and a statistical analysis of these data is performed.

The pressure generated by a gas explosion depends primarily on the percentage of gas in the air and the uniformity of gas-air mixture, the size and shape of the room in which the explosion occurs, and the amount of venting or pressure relief that may occur. Natural gas can only be ignited and exploded when the gas-air mixture contains between 6 percent and 16 percent of gas; the optimum explosion is obtained at a well-mixed percentage of about 10.5 percent. Although in a completely closed chamber with infinitely strong walls explosion pressures can reach as high as $100 \mathrm{psi}\left(690 \mathrm{kN} / \mathrm{m}^{2}\right)$ under optimal conditions, in practice the pressures are much lower. This is the result of imperfect mixing and of venting which occurs when a wall or portion of a boundary surface fails early in the explosion. The pressure at which this venting occurs is termed the venting pressure $p_{y}$; the pressure relief aperture thus formed allows expansion to take place, which reduces the pressure buildup on the remaining surfaces considerably and provides ventilation.

Experimental programs thus have naturally tried to relate a design gas explosion pressure to $p_{V}$ and some measure of the amount of venting provided. Rasbash [48] and Stretch [56] suggested a relation between the peak pressure and the vent pressure and the ratio of the vent area to the smallest bounding surface area in the room. However, this formula was developed from experiments with manufacturered "town" gas, which is more volatile than the natural gas used in the United States [36]. 
In more recent experimental programs reported by Dragosavic [15, 16] tests were conducted with natural gas. A test structure was constructed of reinforced concrete to simulate a domestic kitchen and adjoining living room. In both rooms one side was left open in order to insert and test various types of venting surfaces. Thirty-four (34) separate explosions were produced, tests 1 through 30 taking place only in the kitchen, to determine the effect of various parameters on explosion pressures. Pressures were measured at 10 points on the wall and ceiling for each test. The first 7 tests were preliminary in nature. Tests 8 through 19 were to show the effect of variations in strength and area of the venting surfaces. In tests 20 through 24, the gas-air mixture was varied. (In all other tests in the series, the gas percentage was close to the stoichiometric optimum of 10-10.5 percent.) Tests 25 through 30 were repeats of test 19 and were conducted under nominally identical conditions to indicate predictability. Finally, tests 31 through 34 were conducted to show the effect of room volume and shape and to investigate the strength of an all-brick load bearing wall. In all cases, the maximum measured pressures were recorded. It should be remarked that these tests model an unusually severe situation, the mixture being optimum and uniformly distributed throughout the room.

A typical pressure-time record from one of these tests is shown in figure 18. The total duration of the load is approximately one second. After ignition the pressure rises to the venting pressure $p_{V}$ at which the venting surface fails; thereafter, there may be a small additional rise to $\mathrm{p}_{1}$, after which the pressure drops off. After about $1 / 2$ second, the pressure again increases in a high frequency oscillatory fashion due to turbulent afterburning of traces of gas and resonance of the mass of air between parallel bounding surfaces. Since the frequency of these oscillations is so much higher than the natural frequency of the bounding surfaces, their effect can be essentially ignored in comparison to the mean pressure part $p_{2}$. Moreover, since the frequency of $p_{1}$ and $p_{2}$ is roughly $2 \mathrm{~Hz}$, while the resonant frequencies of masonry walls and concrete panels and floors are about $30 \mathrm{~Hz}-60 \mathrm{~Hz}, p_{1}$ and $p_{2}$ may be treated effectively as static loads for design purposes. A dynamic analysis would be considerably more involved, and does not appear to be warrented in view of the limited data. Within experimental 1 imitations, it appears that $p_{1}$ and $p_{2}$ are attained simultaneously in all parts of the room and the gas explosion thus may be considered to be uniform on all bounding surfaces.

Although $p_{1}$ and $p_{2}$ may be considered as static loads in terms of the dynamic response of the structure the loading rate is still sufficiently accelerated that most structural materials would exhibit some apparent increase in strength. This may be as high as [23] 20-30 percent over those values specified for design. This elevation can either be accounted for by increasing 


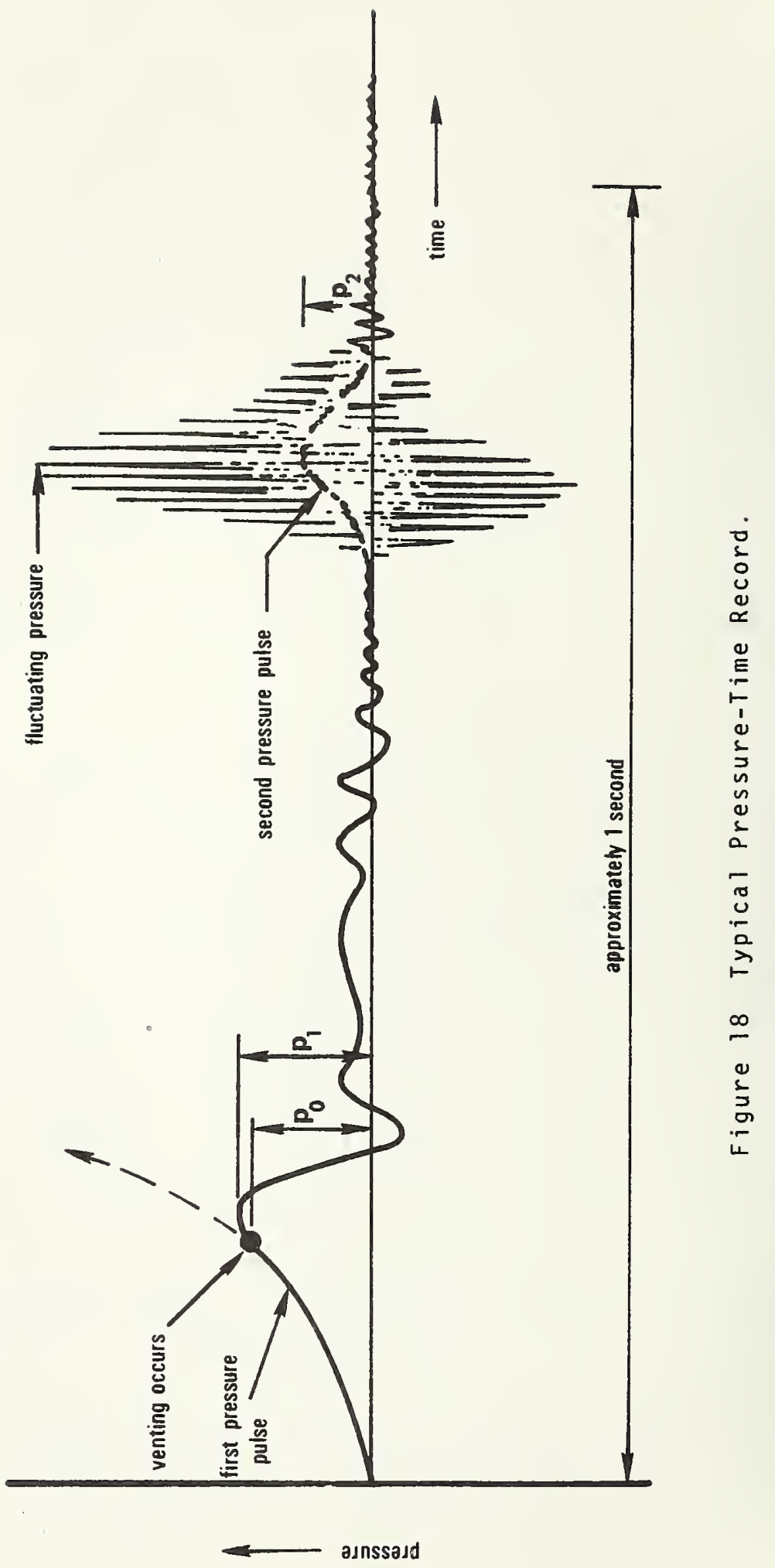


the material strength or reducing the explosion design pressure. In Dragosavic's study, the latter device is employed, resulting in the equivalent static explosion pressures $0.8 \mathrm{p}_{1}$ and $0.8 \mathrm{p}_{2}$ to be used in conjunction with the normal material strength. However, since this reduction is materialdependent and may not always equal $0.8, p_{1}$ and $p_{2}$ are analyzed in the unfactored form in this study.

It is apparent from figure A.I that the first pressure peak, $p_{1}$, and vent vent pressure, $p_{V}$, must be related. Dragosavic proposed the equation

$$
0.8 p_{1}=3+p_{V} \quad\left(k N / m^{2}\right)
$$

as an upper bound estimate. Correlation between $p_{1}$ and $p_{V}$ was confirmed herein by a regression analysis on data obtained from tests 11 through 18 and 30, (these data correspond to figure 16 in reference 16) $p_{1}$ on $p_{V}$, resulting in the equation

$$
\overline{\mathrm{p}}_{1}=1.19 \mathrm{p}_{\mathrm{V}} \quad\left(\mathrm{kN} / \mathrm{m}^{2}\right)
$$

The regression analysis actually estimates the mean $p_{1}$ as a function of $p_{V}$; $p_{1}$ thus averages 19 percent above the venting pressure, as in figure 18 . The standard error is 2.98 and the correlation coefficient is 0.95 .

In general, $p_{V}$ may be calculated from uniformly loaded plate bending formulas [36]. In tests 11,18 and 30 , two panes of glass of unequal size and strength comprised the vent surface. In such cases, it has been recommended [16] that the largest $p_{V}$ be used. The regression analysis appears to confirm this, as when the smaller $p_{V}$ is used in the regression, the correlation coefficient is 0.84 (as opposed to 0.95). However, if only test 30 is eliminated and the regression is performed on the remaining eight (8) data, the opposite conclusion is reached; correlation coefficients of 0.93 and 0.96 are obtained using the large and small values of $p_{V}$, respectively. The existing test data therefore are insufficient to determine the appropriate method for computing $p_{V}$ when the venting surface consists of several panels of unequal strength. In neither case does there appear to be any significant correlation between $p_{1}$ and the amount of venting, however.

A design curve can be obtained by requiring that, say, only 25 percent of the explosion pressures may exceed the design specified value. Assuming that the distribution of pressures about the regression line is roughly normal at any $p_{V}$ with standard deviation of 2.98 , the 25 -percent exceedance probability design curve becomes

$$
\mathrm{p}_{1}=2+1.19 \mathrm{p}_{\mathrm{V}}\left(\mathrm{kN} / \mathrm{m}^{2}\right)
$$

In contrast, Dragosavic's recommended curve corresponds roughly to a 10 percent exceedance probability. 
The second pressure peak $p_{2}$ is also dependent on $p_{V}$, although to a much lesser extent than is $p_{1}$. Since $p_{2}$ occurs subsequent to venting, it is not suprising that $p_{2}$ appears to depend on the effectiveness of the vent in relieving the pressure buildup within the chamber. Dragosavic proposed that where the venting is described by $\psi$, which is the ratio of the venting surface to the total volume of the room, an upper bound to the peak pressures generated by the second pulse is furnished by

$$
0.8 \mathrm{p}_{2}=3+1 / 2 \mathrm{p}_{\mathrm{V}}+\frac{0.04}{\psi^{2}} \quad\left(\mathrm{kN} / \mathrm{m}^{2}\right)
$$

The coefficient $1 / 2$ which is applied to $p_{V}$ reflects the reduced dependence of $\mathrm{p}_{2}$ on $\mathrm{p}_{V}$. However, a regression analysis of the data from tests 11 through 18 and 30 (corresponding to figure 17 in Dragosavic's report) results in the equation

$$
\overline{\mathrm{p}}_{2}=0.6 \mathrm{p}_{\mathrm{V}}+\frac{0.05}{\psi^{2}}-0.91 \quad\left(\mathrm{kN} / \mathrm{m}^{2}\right)
$$

with standard error of 3.19. Using this equation and making similar assumptions as before, a 25 percent exceedance probability design curve for the second pressure oressure nulco haramac

Equation A. 6 on page 60 should read:

$$
p_{V}=1.2+0.6 p_{V}+\frac{0.05}{\psi^{2}} \quad\left(\mathrm{kN} / \mathrm{m}^{2}\right)
$$

for $0.05<y<0.15$, the range over which the data were collected.

$$
\mathrm{p}_{\mathrm{D}}=\max \left(\mathrm{p}_{1}, \mathrm{p}_{2}\right)
$$

This may either be evaluated using equations A. 1 and A.4 (Dragosavic's) recommendation, or using equations $A .3$ and $A .6$, corresponding approximately to a 25 percent exceedance probability.

Tests 19 and 25 through 30 were conducted under nominally identical conditons to provide an indication of the inherent or random variation in the pressure. Analysis of these data revealed that $\bar{p}_{1}=16.44, \delta p_{2}=0.30$, $p_{2}=12.89$, and $\delta p_{2}=0.36$. The latter uncertainty was useful in the Monte-Carlo simulation and in deriving the specific load factors in section 4.2 of the report. 
It should be emphasized that considerable scatter was observed in all these tests and the confidence intervals on the parameter estimates are quite wide. It seems apparent that venting contributes significantly to this variability and more should be learned about its effect. Nevertheless, it is believed that equations A.2 and A.5 provide a reasonable way to estimate the average loads induced by gas explosions. 


\begin{tabular}{|c|c|c|c|}
\hline $\begin{array}{l}\text { U.S. DEPT. OF COMM. } \\
\text { BIBLIOGRAPHIC DATA } \\
\text { SHEET }\end{array}$ & $\begin{array}{l}\text { 1. PUBLICATION OR REPORT NO. } \\
\text { NBS BSS-98 }\end{array}$ & $\begin{array}{l}\text { 2. Gov't Accession } \\
\text { No. }\end{array}$ & 3. Recipient's Accession No. \\
\hline \multirow{3}{*}{\multicolumn{3}{|c|}{$\begin{array}{l}\text { 4. TITLE AND SUBTITLE } \\
\text { Design Methods for Reducing the Risk of Progressive } \\
\text { Collapse in Buildings }\end{array}$}} & 5. Publication Date \\
\hline & & & April 1977 \\
\hline & & & 6. Performing Organization Code \\
\hline \multicolumn{3}{|c|}{ 7. AUTHOR(S) (Sdgar V. Leyendecker and Bruce R. Ellingwood } & 8. Performing Ugan. Report No. \\
\hline \multirow{2}{*}{\multicolumn{3}{|c|}{$\begin{array}{l}\text { 9. PERFORMING ORGANIZATION NAME AND ADDRESS } \\
\text { NATIONAL BUREAU OF STANDARDS } \\
\text { DEPARTMENT OF COMMERCE } \\
\text { WASHINGTON, D.C. } 20234\end{array}$}} & $\begin{array}{l}\text { 10. Project/Task/Work Unit No. } \\
4618488\end{array}$ \\
\hline & & & $\begin{array}{l}\text { 11. Contract/Grant No. } \\
\text { IAA-H-37-72 Task } 408\end{array}$ \\
\hline \multirow{2}{*}{\multicolumn{3}{|c|}{$\begin{array}{l}\text { 12. Sponsoring Organization Name and Complete Address (Street, City, State, ZIP) } \\
\text { Division of Energy, Building Technology, and Standards } \\
\text { Office of Policy Development and Research } \\
\text { Department of Housing and Urban Development } \\
\text { Washington, D. C. } 20410\end{array}$}} & $\begin{array}{l}\text { 13. Type of Report \& Period } \\
\text { Covered } \\
\text { Final Report }\end{array}$ \\
\hline & & & 14. Sponsoring Agency Code \\
\hline
\end{tabular}

15. SUPPLEMENTARY NOTES

Library of Congress Catalog Card Number: 77-608039

16. ABSTRACT (A 200-word or less factual summary of most significant information. If document includes a significant bibliography or literature survey, mention it here.)

A progressive collapse is described as a chain reaction of failures following damage to a relatively small portion of a structure. The damage which results characteristically is out of proportion to the damage which initiated the collapse. The basic concepts associated with progressive collapse are described and the background leading to the concepts is summarized. Possible causes of progressive collapse are discussed, with concentration on abnormal events which have a low probability of occurrence but may have catastrophic consequences. A case study of the probability of structural failure as a consequence of one type of abnormal load (a gas explosion) shows that these probabilities exceed levels generally considered acceptable to engineers.

Direct design strategies for reducing progressive collapse are described as (1) the Alternate Path Method and (2) the Specific Local Resistance Method. Equations for load combinations, including appropriate load factors, are presented for each design method. The advantages and disadvantages of each approach are described and it is concluded that the alternate path method affords the designer more flexibility. Although the design strategies are applicable to any type of structure at any time in its life cycle, this report provides detailed recommendations for completed buildings.

17. KEY WORDS (six to twelve entries; alphabetical order; capitalize only the first letter of the first key word unless a proper name; separated by semicolons) Abnormal loading; alternate path; building code; design criteria; probability; progressive collapse; reliability; structural engineering; uncertainty.

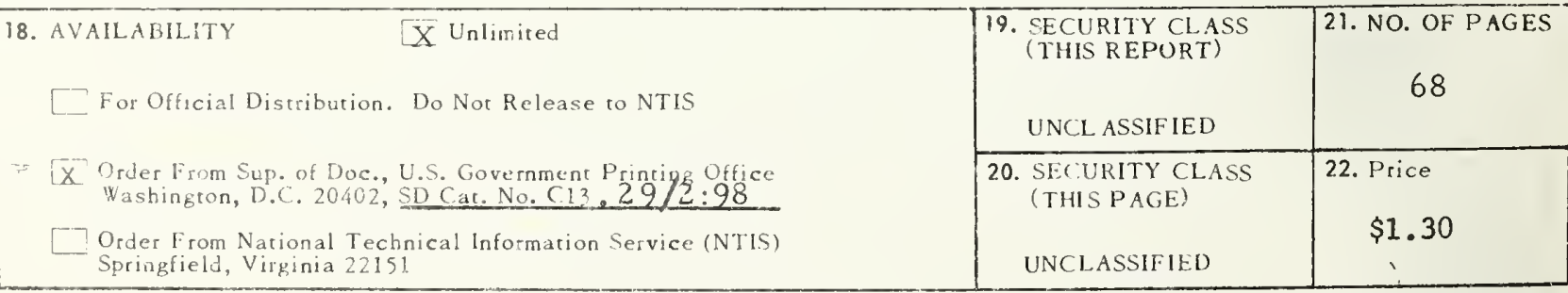




\section{BACK BY \\ POPULAR DEMAND}

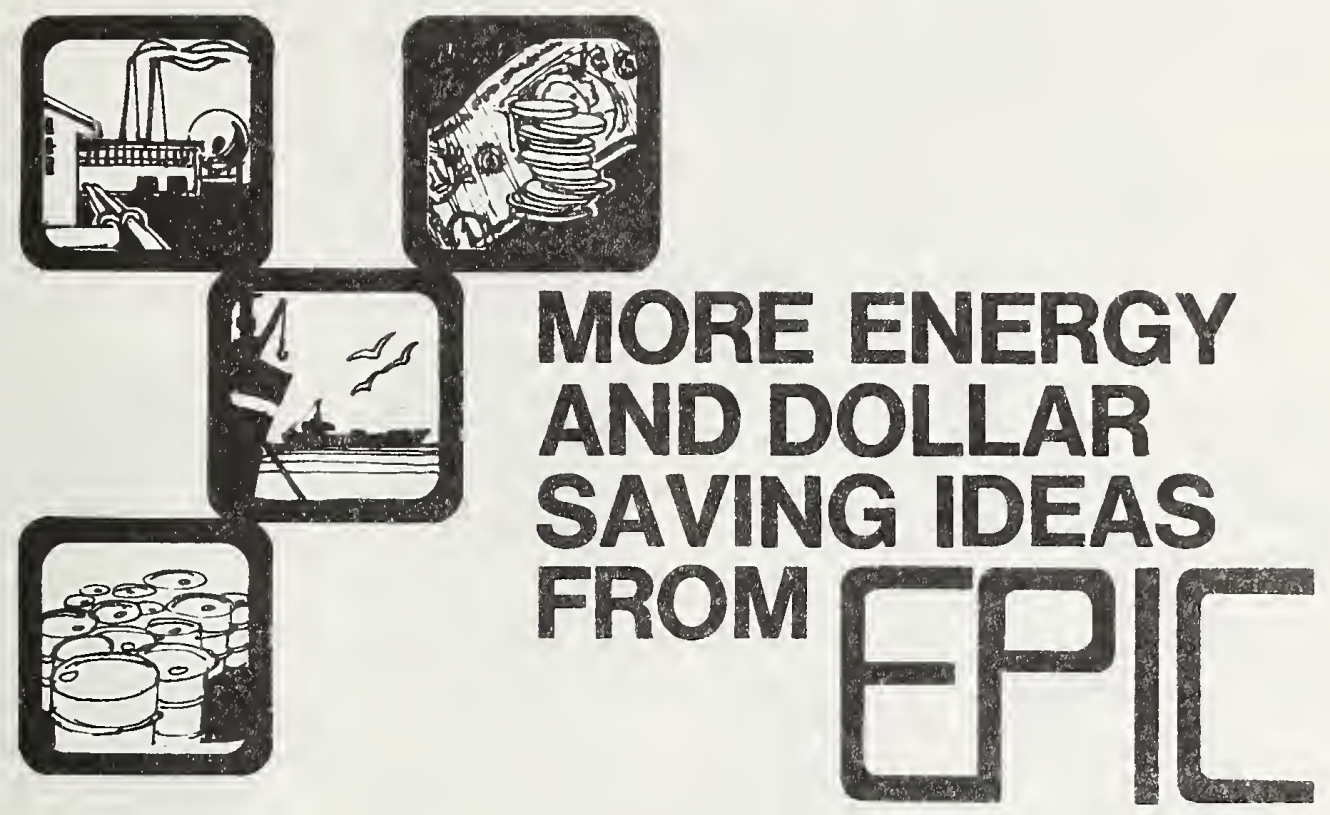

for you, the cost-conscious manager, in a new supplement to EPIC.

This first EPIC Supplement builds on the success of the original Energy Conservation Program Guide for Industry and Commerce, a comprehensive handbook that has helped thousands of managers establish or improve energy conservation programs in their organizations.

In the 89-page EPIC Supplement, you will find:

- A reorganized and simplified explanation of how to implement an energy conservation program.

- More than 50 additional Energy Conservation Opportunities to save energy in 13 different functional and operating areas.

- Two dozen new case studies that let you estimate your potential for conserving energy and reducing costs.

- New sources of assistance.
Industrial and commercial firms, hospitals, universities, research institutes, public utilities-ANY organization-whatever its size-that uses energy and has to pay the bills will want a copy of the EPIC Supplement.

The EPIC Supplement is intended to be used with the original EPIC guide. If you already have a copy of EPIC, don't delay in ordering the Supplement. Make EPIC part of your continuing plan to control energy use and costs.

To order your copy of EPIC Supplement, send $\$ 2.25$ per copy (check, money order, or Superintendent of Documents coupons) to Superintendent of Documents, U.S. Government Printing Office, Washington, D.C. 20402. Use S.D. Catalog Number C13.11:115/1. To order EPIC, send $\$ 2.90$ a copy to Superintendent of Documents, S.D. Catalog Number C13.11:115. Discount of $25 \%$ on orders of 100 copies or more mailed to one address. 


\section{ARE YOU}

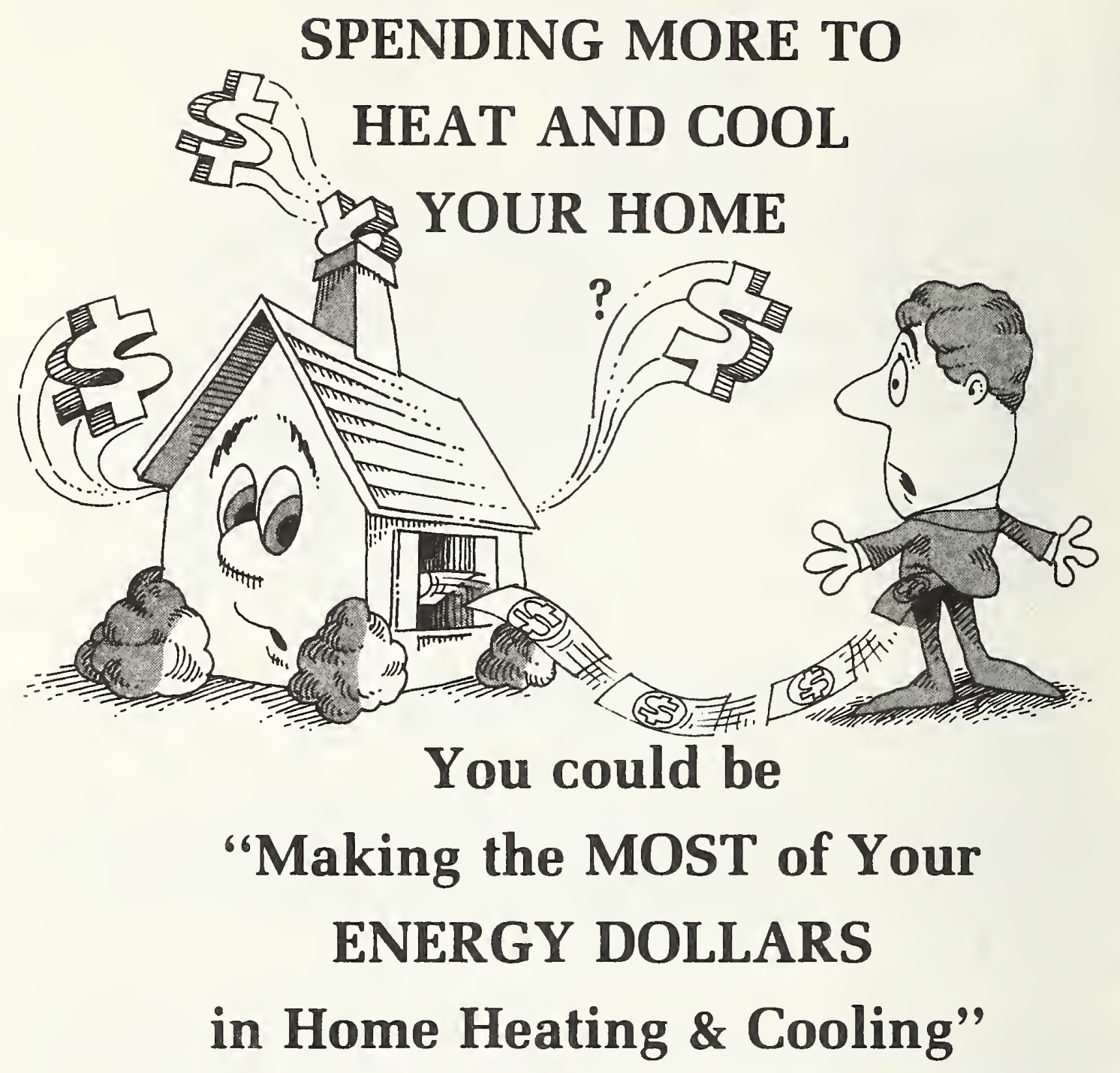

Making the Most of Your Energy Dollars is a new consumer guide from the Commerce Department's National Bureau of Standards, in cooperation with the Federal Energy Administration.

For your climate and the type of energy used to heat and cool your house, this booklet lets you find your best investment in energy conservation improvements. This investment gives you the greatest possible net savings in your heating and cooling bills over the long run.

Use the booklet to figure out just how much insulation, storm windows and doors, weather stripping and caulking are needed for your house-and what they will cost. Not a how-to-do-it book, but a "how-much" guide to energy conservation investments.

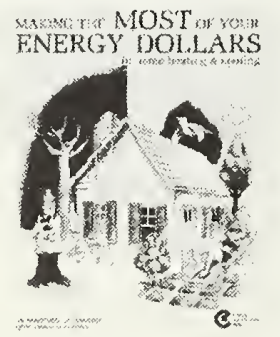

To make the most of YOUR energy dollars send $\$ 0.70$ per copy (check, money order or Superintendent of Documents Coupons) to Consumer Information, Public Documents Distribution Center, Pueblo, Colorado 81009. Ask for Making the Most of Your Energy Dollars in Home Heating and Cooling. 


\section{PERIODICALS}

JOURNAL OF RESEARCH reports National Bureau of Standards research and development in physics, mathematics, and chemistry. It is published in two sections, available separately:

- Physics and Chemistry (Section A)

Papers of interest primarily to scientists working in these fields. This section covers a broad range of physical and chemical research, with major emphasis on standards of physical measurement, fundamental constants, and properties of matter. Issued six times a year. Annual subscription: Domestic, $\$ 17.00$; Foreign, $\$ 21.25$.

- Mathematical Sciences (Section B)

Studies and compilations designed mainly for the mathematician and theoretical physicist. Topics in mathematical statisties, theory of experiment design, numerical analysis, theoretical physics and chemistry, logical design and programming of computers and computer systems. Short numerical tables. Issued quarterly. Annual subscription: Domestic, $\$ 9.00$; Foreign, $\$ 11.25$.

DIMENSIONS/NBS (formerly Technical News Bulletin)-This monthly magazine is published to inform scientists, engineers, businessmen, industry, teachers, students, and consumers of the latest advances in science and technology, with primary emphasis on the work at NBS. The magazine highlights and reviews such issues as energy research, fire protection, building technology, metric conversion, pollution abatement, health and safety, and consumer product performance. In addition, it reports the results of Bureau programs in measurement standards and techniques, properties of matter and matsrials, engineering standards and services, instrumentation, and automatic data processing.

Annual subscription: Domestic, \$12.50; Foreign, \$15.65.

\section{NONPERIODICALS}

Monographs-Major contributions to the technical literature on various subjects related to the Bureau's scientific and technical activities.

Handbooks-Recommended codes of engineering and industrial practice (including safety codes) developed in cooperation with interested industries, professional organizations, and regulatory bodies.

Special Publications-Include proceedings of conferences sponsored by NBS, NBS annual reports, and other special publications appropriate to this grouping such as wall charts, pocket cards, and bibliographies.

Applied Mathematics Series-Mathematical tables, manuals, and studies of special interest to physicists, engineers, chemists, biologists, mathematicians, computer programmers, and others engaged in scientific and technical work.

National Standard Reference Data Series-Provides quantitative data on the physical and chemical properties of materials, compiled from the world's literature and critically evaluated. Developed under a world-wide program coordinated by NBS. Program under authority of National Standard Data Act (Public Law 90-396).
NOTE: At present the principal publication outlet for these data is the Journal of Physical and Chemical Reference Data (JPCRD) published quarterly for NBS by the American Chemical Society (ACS) and the American Institute of Physics (AIP). Subscriptions, reprints, and supplements available from ACS, 1155 Sixteenth St. N.W., Wash. D. C. 20056.

Building Science Series-Disseminates technical information developed at the Bureau on building materials, components, systems, and whole structures. The series presents research results, test methods, and performance criteria related to the structural and environmental functions and the durability and safety characteristics of building elements and systems.

Technical Notes-Studies or reports which are complete in themselves but restrictive in their treatment of a subject. Analogous to monographs but not so comprehensive in scope or definitive in treatment of the subject area. Often serve as a vehicle for final reports of work performed at NBS under the sponsorship of other government agencies.

Voluntary Product Standards-Developed under procedures published by the Department of Commerce in Part 10. Title 15, of the Code of Federal Regulations. The purpose of the standards is to establish nationally recognized requirements for products, and to provide all concerned interests with a basis for common understanding of the characteristics of the products. NBS administers this program as a supplement to the activities of the private sector standardizing organizations.

Consumer Information Series-Practical information, based on NBS research and experience, covering areas of interest to the consumer. Easily understandable language and illustrations provide useful background knowledge for shopping in today's technological marketplace.

Order above NBS publications from: Superintendent of Documents, Government Printing Office, Washington, D.C. 20402 .

Order following NBS publications-NBSIR's and FIPS from the National Technical Information Services, Springfield, Va. 22161.

Federal Information Processing Standards Publications (FIPS PUBS)-Publications in this series collectively constitute the Federal Information Processing Standards Register. Register serves as the official source of information in the Federal Government regarding standards issued by NBS pursuant to the Federal Property and Administrative Services Act of 1949 as amended, Public Law 89-306 (79 Stat. 1127), and as implemented by Executive Order 11717 ( 38 FR 12315, dated May 11, 1973) and Part 6 of Title 15 CFR (Code of Federal Regulations).

NBS Interagency Reports (NBSIR)-A special series of interim or final reports on work performed by NBS for outside sponsors (both government and non-government). In general, initial distribution is handled by the sponsor; public distribution is by the National Technical Information Services (Springfield, Va. 22161) in paper copy or microfiche form.

\section{BIBLIOGRAPHIC SUBSCRIPTION SERVICES}

The following current-awareness and literature-survey bibliographies are issued periodically by the Bureau: Cryogenic Data Center Current Awareness Service. A literature survey issued biweekly. Annual subscription: Domestic, $\$ 20.00$; Foreign, $\$ 25.00$.

Liquified Natural Gas. A literature survey issued quarterly. Annual subscription: $\$ 20.00$.
Superconducting Devices and Materials. A literature survey issued quarterly. Annual subscription: $\$ 20.00$. Send subscription orders and remittances for the preceding bibliographic services to National Bureau of Standards, Cryogenic Data Center (275.02) Boulder, Colorado 80302. 
U.S. DEPARTMENT OF COMMERCE

National Buraau of Btandards

Washington, D.C. 20234

OFFICIAL BUSINESS

Penalty for Private Use. $\$ 300$
POSTAGE ANO FEES PAID U.S. DEPARTMENT OF COMMERCE $C O M=215$

SPECIAL FOURTH-CLASS RATE BOOK

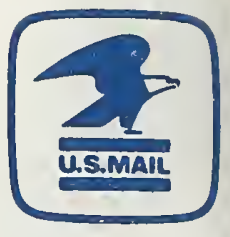

